\title{
Plant Proteases: From Phenotypes to Molecular Mechanisms
}

\author{
Renier A. L. van der Hoorn \\ Plant Chemetics Lab, Max Planck Institute for Plant Breeding Research, Cologne, \\ Germany 50829 and Chemical Genomics Center of the Max Planck Society, \\ Dortmund, Germany 44227; email: hoorn@mpiz-koeln.mpg.de
}

Annu. Rev. Plant Biol. 2008. 59:191-223

The Annual Review of Plant Biology is online at plant.annualreviews.org

This article's doi:

10.1146/annurev.arplant.59.032607.092835

Copyright (C) 2008 by Annual Reviews. All rights reserved

$1543-5008 / 08 / 0602-0191 \$ 20.00$

\section{Key Words}

phytocalpain, papain-like cysteine proteases, deconjugating proteases, subtilases, serine carboxypeptidase-like proteases, pepsin-like aspartic proteases

\begin{abstract}
Plant genomes encode hundreds of proteases, which represent dozens of unrelated families. The biological role of these proteases is mostly unknown, but mutant alleles, gene silencing, and overexpression studies have provided phenotypes for a growing number of proteases. The aim of this review is to show the diversity of the processes that are regulated by proteases, and to summarize the current knowledge of the underlying molecular mechanisms. The emerging picture is that plant proteases are key regulators of a striking variety of biological processes, including meiosis, gametophyte survival, embryogenesis, seed coat formation, cuticle deposition, epidermal cell fate, stomata development, chloroplast biogenesis, and local and systemic defense responses. The functional diversity correlates with the molecular data: Proteases are specifically expressed in time and space and accumulate in different subcellular compartments. Their substrates and activation mechanisms are elusive, however, and represent a challenging topic for further research.
\end{abstract}




\section{Contents}

INTRODUCTION............... 192

CYSTEINE PROTEASES ......... 195

Phytocalpain DEK1 ............ 195

Papain-Like Proteases Rcr3 and NbCathB............. 197

Deconjugating Enzymes UCH1/2 and ESD4............... 199

Caspase-Like Proteases MCAs and VPEs .................. 201

SERINE PROTEASES ........... 204

Subtilisin-Like Proteases SDD1 and ALE1 ............... 204

Carboxypeptidase-Like Proteases SNG1/2 and BRS1 ......... 206

METALLOPROTEASES ......... 208

Clan MA Metalloproteases MPA1 and VAR1/2 ............. 208

Metalloproteases AMP1 and EGY1. 210

ASPARTIC PROTEASES .......... 212

Pepsin-Like Proteases CDR1 and PCS1 ................ 212

CONCLUSIONS................. 214

\section{INTRODUCTION}

As in the case of all other organisms, plants use proteases to degrade nonfunctional proteins into amino acids. This is common textbook knowledge, but there is more to proteases than this housekeeping function. Proteases are also key regulators. By irreversibly determining the fate of other proteins, they regulate different processes in response to developmental and environmental

MEROPS: protease database, named after a tropical bird living in families and clans

Clan: group of protease families that share the same ancestor

Family: group of proteases that share a certain level of sequence homology cues. This implies that proteases are substrate specific, and that their activity is tightly regulated, both in time and space. Testimony for the existence of regulatory proteases in plants is relatively recent and is summarized in this review.

Proteases cleave peptide bonds that can be internal (for endopeptidases), N-terminal (for aminopeptidases), or C-terminal (for carboxypeptidases). All proteases polarize the carbonyl group of the substrate peptide bond by stabilizing the oxygen in an oxyanion hole, which makes the carbon atom more vulner- able for attack by an activated nucleophile (Figure 1a). Proteases can do this in four major ways, which gives the names to four catalytic classes: cysteine proteases, serine proteases, metalloproteases, and aspartic proteases (30) (Figure 1 $\boldsymbol{b}$ ).

Proteases in the MEROPS protease database have been subdivided into families and clans on the basis of evolutionary relationships (http://merops.sanger.ac.uk) (69). The Arabidopsis genome encodes over 800 proteases, which are distributed over almost 60 families, which belong to 30 different clans (Figure $2 \boldsymbol{b}$ ). The distribution and the family size are well conserved within the plant
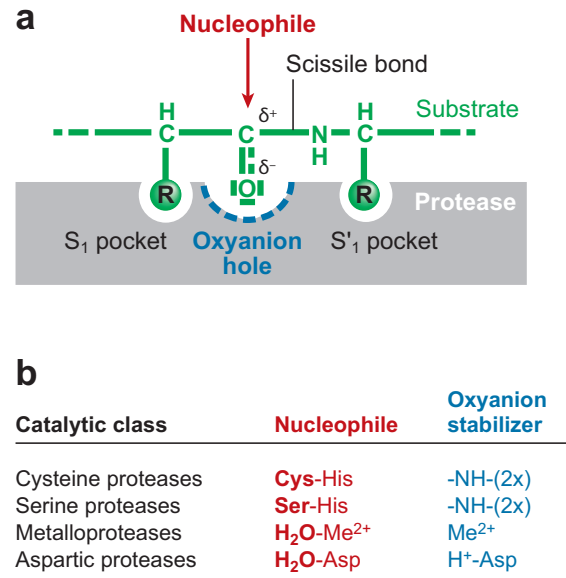

Figure 1

Cleavage mechanisms of the four major catalytic classes of proteases. (a) The substrate protein (green) binds via amino acid residues (R) to the substrate binding site of the protease ( gray) by interacting with substrate (S) pockets of the enzyme. The scissile peptide bond is adjacent to a carbonyl group, which is polarized by the enzyme by stabilizing the oxyanion hole (blue); this makes the carbonyl carbon vulnerable for nucleophilic attack. $(b)$ The major differences between the catalytic classes are the nature of the nucleophile and oxyanion stabilizer. Cysteine and serine proteases use a Cys or Ser residue as nucleophile, activated by histidine (His) in the active site. The oxyanion hole is usually stabilized by two residues in the backbone of the protease. Metalloproteases and aspartic proteases use water as nucleophile, activated by electrostatic interactions with the metal ion $\left(\mathrm{Me}^{2+}\right)$ or aspartate (Asp), respectively. The oxyanion of these proteases is stabilized by $\mathrm{Me}^{2+}$ and Asp, respectively. 


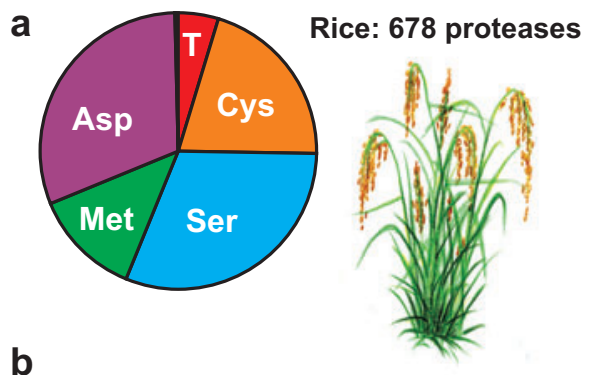

b
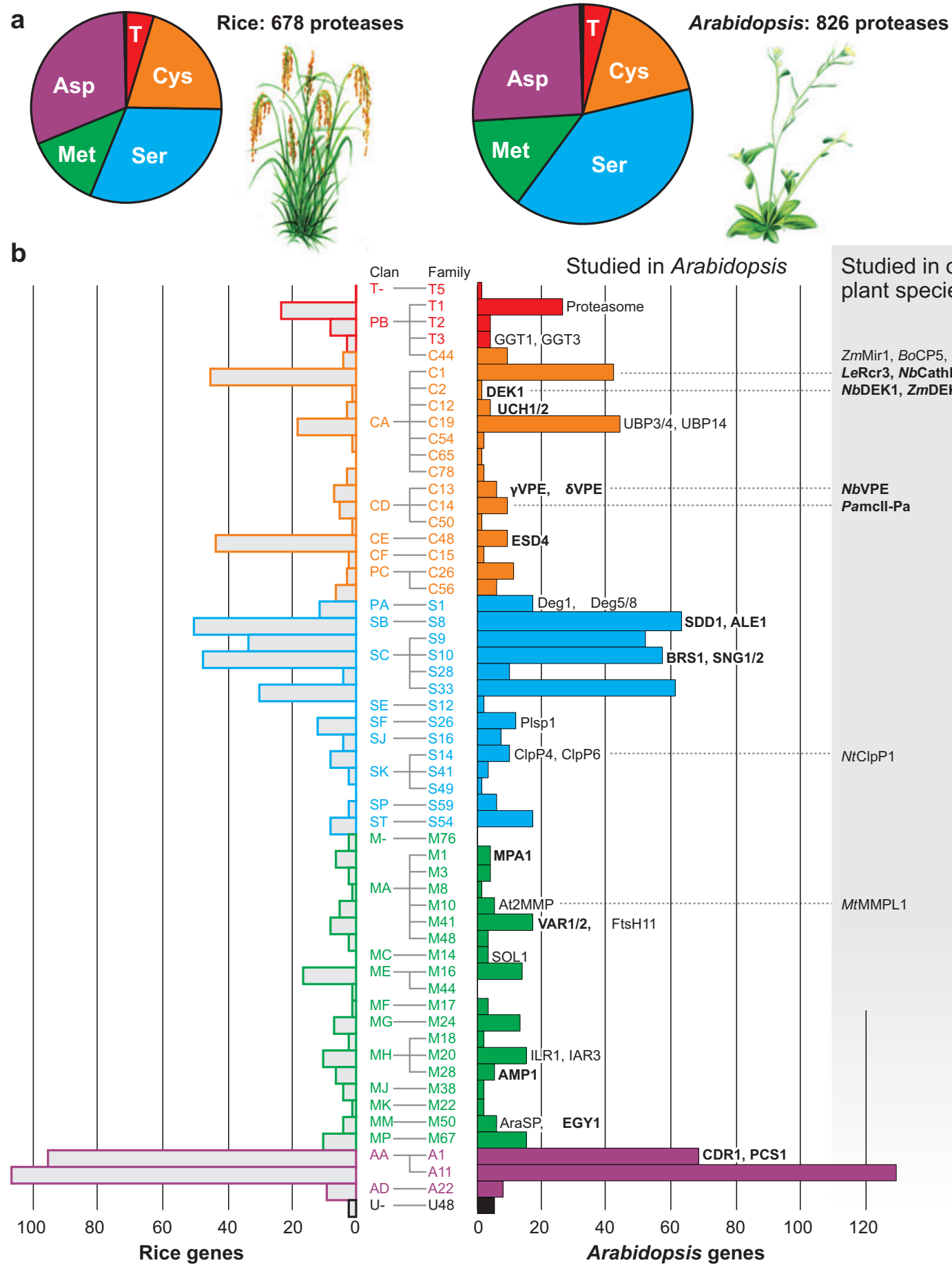

conn fand PB

$\mathrm{B}-\mathrm{T} 1$

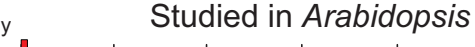

Studied in other

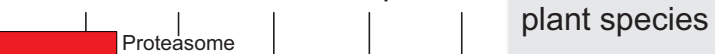

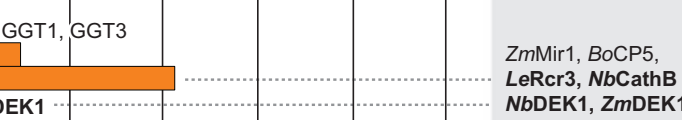

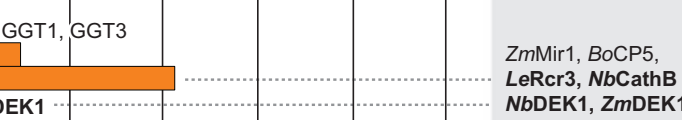

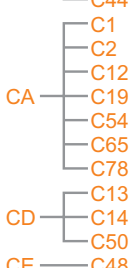
$\mathrm{CE}-\mathrm{C} 48$
$\mathrm{CF}-\mathrm{C} 15$ $\mathrm{PC}-\mathrm{C} 26$ $\mathrm{PA}-\mathrm{S} 1$ $\mathrm{SB}-\mathrm{S} 8$ SC - S 59 $\mathrm{S} 28$
$\mathrm{~S} 33$ SE $-\mathrm{S} 12$ SF $-\mathrm{S} 26$ SK $-\mathrm{S} 14$ SK - $\begin{array}{r}\text { S41 } \\ \text { S49 }\end{array}$ SP $-\mathrm{S} 59$ ST - S54 M- - M76 \begin{tabular}{l|l} 
& $\mathrm{M} 1$ \\
$\mathrm{MA}$ & $\mathrm{M} 3$ \\
& $\mathrm{M} 8$
\end{tabular} $M A-M 8$ $-\mathrm{M} 41$
$-\mathrm{M} 48$ $M C-M 14$ ME $-\mathrm{M} 16$ M17 $M G-M 24$ $\begin{array}{rr}\mathrm{MH} & \mathrm{M} 18 \\ & \mathrm{M} 20\end{array}$ MJ $\begin{array}{r}-M 28 \\ -M 38\end{array}$ $\mathrm{MK}-\mathrm{M} 22$ $\mathrm{MM}-\mathrm{M} 50$ $\mathrm{MP}-\mathrm{M} 67$ $A A-A 1$ $A D=A 22$ UCH1/2 UBP3/4, UBP14
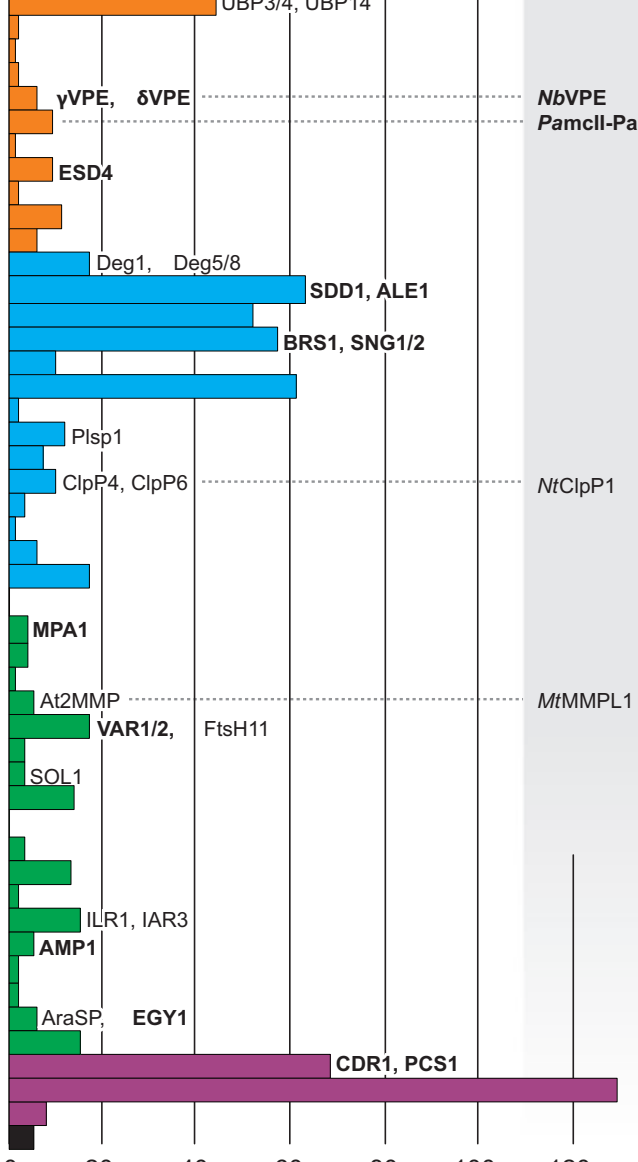

Figure 2

Distribution of rice (left) and Arabidopsis (right) protease genes over $(a)$ the different catalytic classes, and (b) the different families (right) and clans (left). Proteases for which biological roles are known from genetic experiments are indicated on the right (see also Table 1). Proteases discussed in this article are indicated in bold. 
Table 1 Proteases with known phenotypes

\begin{tabular}{|c|c|c|c|c|c|}
\hline $\begin{array}{l}\text { Name of } \\
\text { protease }^{\mathrm{a}}\end{array}$ & Accession & Species $^{b}$ & Family & Phenotype observed ${ }^{c}$ & Reference \\
\hline GGT1 & At4g39640 & At & T3 & KO: premature senescence after flowering & 59 \\
\hline GGT3 & At1g69820 & At & T3 & KO: reduced number of siliques and seeds & 59 \\
\hline Rcr3 & AF493234 & $L e$ & C1A & KO: loss of recognition of fungal pathogen & 49 \\
\hline NbCathB & DQ492297 & $\mathrm{Nb}$ & C1A & KD: suppressed hypersensitive cell death & 35 \\
\hline Mir1 & AAB70820 & $Z m$ & C1A & OE: inhibits caterpillar growth & 67 \\
\hline $\mathrm{BoCP5}$ & AF454960 & Bo & C1A & KD: suppresses broccoli postharvest senescence & 31 \\
\hline$\overline{\text { DEK1 }}$ & AY061804 & $Z m$ & $\mathrm{C} 2$ & KO: no/reduced aleurone on kernels & 7 \\
\hline NbDEK1 & AY450851 & $\mathrm{Nb}$ & $\mathrm{C} 2$ & KD: callus-like surface on all organs & 1 \\
\hline$\overline{A t D E K 1}$ & At1g55350 & At & $\mathrm{C} 2$ & KD: altered epidermal cell fate & 43 \\
\hline $\mathrm{UCH} 1 / 2$ & At5g16310 & At & $\mathrm{C} 12$ & KO: more branches; OE: less branches & 101 \\
\hline UBP1/2 & At1g177110 & At & C19 & KO: enhanced susceptibility to canavanine & 100 \\
\hline UBP3/4 & At4g39910 & At & C19 & KO: impaired pollen development & 26 \\
\hline UBP14 & At3g20630 & At & C19 & KO: embryos arrest at the globular stage & 27 \\
\hline NbVPE & $\mathrm{AB} 181187$ & $\mathrm{Nb}$ & $\mathrm{C} 13$ & KD: blocked hypersensitive cell death & 38 \\
\hline$\gamma \mathrm{VPE}$ & At4g32940 & At & $\mathrm{C} 13$ & KO: reduced toxin-induced cell death & 51 \\
\hline SVPE & At3g20210 & At & C13 & KO: delayed cell death in seed coat & 65 \\
\hline mcII-Pa & AJ534970 & $P a$ & C14 & KD: reduced cell death during embryogenesis & 12 \\
\hline ESD4 & At4g15880 & At & $\mathrm{C} 48$ & KO: early flowering, pleiotropic effects & 64 \\
\hline Deg1 & At3g27925 & At & S1 & KD: reduced growth, early flowering & 46 \\
\hline $\operatorname{Deg} 5(/ 8)$ & At4g18370 & At & S1 & KO: reduced growth under high light & 85 \\
\hline SDD1 & At1g04110 & At & S8 & KO: altered stomata density and distribution & 9 \\
\hline ALE1 & At1g62340 & At & S8 & KO: lacks embryo cuticle & 88 \\
\hline BRS1 & At4g30610 & At & S10 & OE: enhanced BR sensitivity & 54 \\
\hline SNG1 & At2g22990 & At & S10 & KO: no sinapoylmalate biosynthesis in leaves & 52 \\
\hline SNG2 & At5g09640 & At & S10 & KO: no sinapoylcholine biosynthesis in seeds & 82 \\
\hline Plsp1 & At3g24590 & At & S26 & KO: reduced plastid internal membranes, lethal & 42 \\
\hline $\mathrm{ClpP} 4$ & At5g45390 & At & S14 & KD: bleached leaves; OE: chlorotic rosette leaves & 80,105 \\
\hline $\mathrm{ClpP} 1$ & Z00044 & $N t$ & S14 & KO: ablation of shoot system & 50 \\
\hline ClpP6 & Atlg11750 & At & S14 & KD: chlorotic young rosette leaves & 83 \\
\hline MPA1 & At1g63770 & At & M1 & KO: disturbed meiotic chromosome segregation & 78 \\
\hline At2MMP & At1g70170 & At & M10 & KO: slow growth, late flowering, early senescence & 36 \\
\hline MMPL1 & Y18249 & $M t$ & M10 & KD: larger infection threads; OE: aborted infection & 21 \\
\hline VAR1 & At5g42270 & At & M41 & KO: variegated leaves, stems, and siliques & 76 \\
\hline VAR2 & At2g30950 & At & M41 & KO: variegated leaves, stems, and siliques & 18 \\
\hline FtsH11 & At5g53170 & At & M41 & KO: loss of thermotolerance & 16 \\
\hline SOL1 & At1g71696 & At & M14 & KO: suppressor of restricted root meristem & 13 \\
\hline ILR1 & At $3 g 02875$ & At & M20 & KO: insensitive to exogenous IAA-Leu & 4 \\
\hline$\overline{\text { IAR3 }}$ & At1g51760 & At & M20 & KO: reduced sensitivity to exogenous IAA-Ala & 23 \\
\hline AMP1 & At3g54720 & At & M28 & KO: oversized meristems, polycotyly, etc. & 39 \\
\hline$\overline{\mathrm{AraSP}}$ & At2g32480 & $A t$ & M50 & $\begin{array}{l}\text { KD/KO: impaired chloroplast and seedling } \\
\text { development }\end{array}$ & 10 \\
\hline EGY1 & At5g35220 & At & M50 & KO: reduced chlorophyl and gravitropism & 15 \\
\hline
\end{tabular}


Table 1 (continued)

\begin{tabular}{|c|c|c|c|c|c|}
\hline Name of protease ${ }^{a}$ & Accession & Species $^{b}$ & Family & Phenotype observed $^{c}$ & Reference \\
\hline CDR1 & At5g33340 & At & A1 & OE: constitutive disease resistance; dwarfing & 98 \\
\hline PCS1 & At5g02190 & At & A1 & KO: lethality in gametophytes and embryos & 34 \\
\hline
\end{tabular}

${ }^{\text {a }}$ Proteases discussed in text are indicated in bold.

${ }^{\mathrm{b}}$ At, Arabidopsis thaliana; Bo, Brassica oleracea; Le, Lycopersicon esculentum; Mt, Medicago trunculata; Nb, Nicotiana benthamiana; Nt, Nicotiana tabacum; Os, Oryza sativa; Pa, Picea abies; Zm, Zea mays.

${ }^{\mathrm{c}} \mathrm{KO}$, knockout; KD, knockdown/silencing/RNAi; OE, overexpression; IAA, indole acetic acid.

kingdom because poplar and rice have similar distributions (33) (Figure 2b).

The biological functions of at least 40 proteases have been revealed through genetic studies (Table 1). The diversity of the biological functions is tremendous and stretches out over the entire spectrum of proteases. The proteases functionally described so far belong to $\sim 20$ different families of 14 clans (Figure $2 \boldsymbol{b}$ ). Although the phenotypes associated with altered expression of these proteases have been well described, research addressing their molecular mechanisms has only just begun. Interestingly, not all annotated proteases cleave peptide bonds in proteins. MEROPS peptidase T3 family members $\gamma$-glutamyltransferase 1 and 2 (GGT1 and GGT2), for example, hydrolyze the tripeptide glutathione and glutathione Sconjugates (59), whereas the MEROPS peptidase M20 family members indole acetic acid (IAA)-amino acid hydrolase (ILR1) and IAAalanine resistant 3 (IAR3) hydrolyze auxinamino acid conjugates $(4,23)$. One subclass of the S10 carboxypeptidases catalyzes acyltransferase reactions, rather than proteolysis (SNG1/2, discussed below).

This review summarizes the phenotypic data for a broad spectrum of plant proteases and discusses their molecular mechanisms. I focus on seventeen proteases that are relatively well described at a phenotypic level. The biological function of each of these proteases is so distinct that I choose to treat them separately and group them on the basis of the MEROPS classification. The summarized data illustrate that proteases play strikingly diverse regulatory roles in a broad spectrum of processes essential for a plant's life.

\section{CYSTEINE PROTEASES}

Cysteine proteases use a catalytic Cys as a nucleophile during proteolysis. Plant genomes encode for approximately 140 cysteine proteases that belong to 15 families of 5 clans (69). The structures of proteases from different clans are distinct, which implicates convergent evolution. Clans CA and CE contain proteases with a papain-like fold, whereas $\mathrm{CD}$ proteases have a caspase-like fold (explained below). Many cysteine proteases play a role in programmed cell death (PCD), in response to both developmental cues and pathogens. Other cysteine proteases regulate epidermal cell fate, flowering time, inflorescence architecture, and pollen or embryo development (Table 1). Seven of these proteases have been studied in detail and are discussed here.

\section{Phytocalpain DEK1}

Calpains (family C2, clan CA) are well studied calcium-dependent proteases in animals that usually act in the cytoplasm (74). Calpains are evolutionarily related to papain because they share the same fold and order of catalytic residues (Cys, His, Asn) (40). Calpains are folded as two lobes, one carries the catalytic Cys and the other carries His and Asn residues, and the catalytic triad is assembled between the lobes. In calpains, the distance between the lobes, and thereby the functionality of the catalytic triad, is regulated by calcium binding (40). Plant genomes

\section{Convergent} evolution: independent evolution toward a similar functional endpoint

Programmed cell death (PCD): cell death in which cell signaling is required for cells to die 

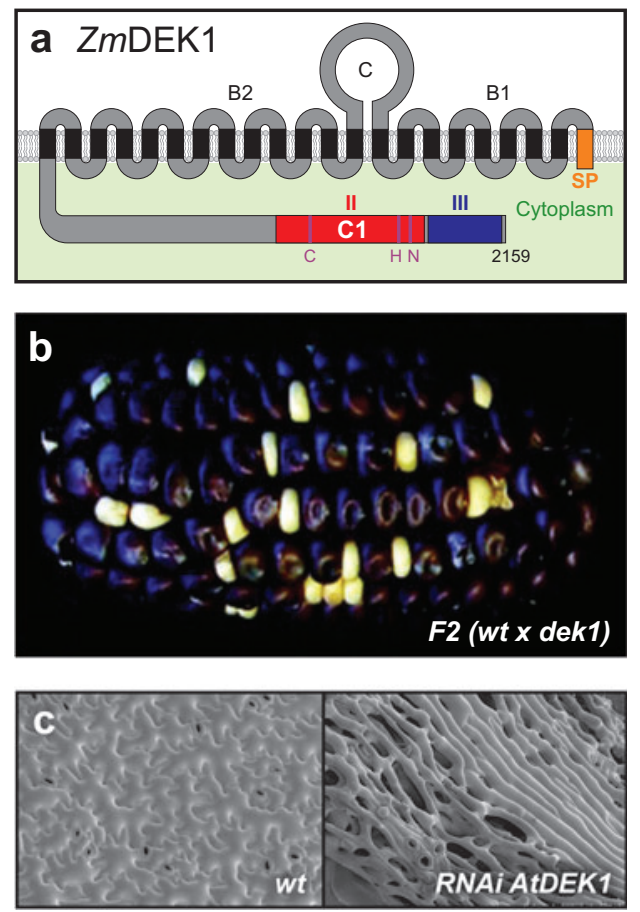

Figure 3

DEK1 (a) Predicted topology of the Zea mays defective kernel 1 (DEK1) protein. SP, signal peptide; B1, B2, transmembrane domains (black); C, extracytoplasmic loop; II, calpain protease domain (red); III, calpain domain III (dark blue); C, H, N, catalytic residues Cys, His, and Asn (purple). (b) Phenotype of a maize ear of a heterozygous dek1 mutant in a genetic background that stains the aleurone layer black. The dek 1 mutation is recessive and causes loss of the aleurone layer in the homozygous state. Reprinted with permission from Reference 55, Copyright 2002, National Academy of Sciences, U.S.A. (c) Silencing of AtDEK1 in Arabidopsis results in loss of epidermal cell identity: Epidermal cells are gradually replaced by mesophyll-like cells. Pictures kindly provided by Dr. G. Ingham (Institute for Molecular Plant Sciences, Edinburgh, UK).

contain only one calpain, also called phytocalpain, which is unique in its structure (Figure $3 \boldsymbol{a}$ ) and essential for plant epidermis development.

DEK1. Defective kernel 1 (DEK1) (Table 2) is required for epidermal cell identity. The dek1 mutation was originally identified in maize where it causes defective kernels that lack an aleurone cell layer (6) (Figure 3b). Although the aleurone is initiated in young endosperm, it is not maintained in dek $1 \mathrm{mu}-$ tants (55). A series of twelve maize dek1 alleles was described with phenotypes that range from aborted embryos to viable plants that have crinkled leaves, shortened internodes, and bent nodes (7). Revertant sector analysis revealed that DEK1 functions cell-autonomously because wild-type cells cannot rescue the phenotype of adjacent dek1 mutant cells, and dek1 mutant cells cannot impose their phenotype onto adjacent wild-type cells (7). The maize dek1 phenotypes are similar to those described in other plant species. Arabidopsis dek1 mutants develop only a partial aleurone and the embryos abort during development (43, 56). Mutant embryos that develop to the globular stage show uncontrolled planes of cell division in the suspensor and embryo proper $(43,56)$. Suppression of AtDek1 transcript levels via the use of RNAi permits the growth of viable plants. The phenotypes vary in severity from fused cotyledons to leaf epidermal cells that are gradually replaced by mesophyl-like cells that contain chloroplasts (43) (Figure 3c). Suppression of NbDek1 transcript levels via the use of virus-induced gene silencing in Nicotiana benthamiana results in hyperproliferation of epidermal cells and the formation of callus-like surfaces on leaves, stems, and flowers (1). Interestingly, despite the severe epidermal phenotypes caused by the loss of Dek1, the basic organization of inner leaf tissues is maintained, with normal palisade and mesophyll cells $(1,7,56)$. AtDEK1-overexpressing Arabidopsis plants lack trichomes and show altered surface structures of leaves, ovules, and seeds (56). Taken together, these phenotypes indicate that DEK1 is essential for epidermal cell identity, and epidermal cell identity is essential for the development of the embryo, the suspensor, and the shoot apical meristem, but not the endosperm and mesophyll (43).

The DEK1 protein contains an exceptionally high number of transmembrane domains (21), interrupted by a putative extracytoplasmic domain (55). The C-terminal domain is presumably cytoplasmic and shares homology with calpain (55). Apart from its unusual structure, DEK1 is also unique because it is highly 
Table 2 Phytocalpain DEK1 (defective kernel 1)

\begin{tabular}{|c|c|c|c|}
\hline Gene name & DEK1 & AtDEK1 & NbDEK1 \\
\hline Described alleles & $\operatorname{Dek1-1\ldots 12(7)}$ & Dek1-1...4 (43, 56) & \\
\hline $\begin{array}{l}\text { Knockout } \\
\text { phenotype }\end{array}$ & $\begin{array}{l}\text { Aleurone deficient, embryo } \\
\text { abortion }(6,7,55)\end{array}$ & $\begin{array}{l}\text { Aleurone deficient, embryo } \\
\text { abortion }(43,56)\end{array}$ & Not reported \\
\hline $\begin{array}{l}\text { Knockdown } \\
\text { phenotype }\end{array}$ & Not reported & $\begin{array}{l}\text { Deformed plants lacking } \\
\text { epidermis (43) }\end{array}$ & $\begin{array}{l}\text { Callus formation on all surfaces } \\
\text { (1) }\end{array}$ \\
\hline $\begin{array}{l}\text { Overexpression } \\
\text { phenotype }\end{array}$ & Not reported & $\begin{array}{l}\text { Loss of trichomes, different } \\
\text { epidermal cell shape, but not } \\
\text { in all ecotypes (56) }\end{array}$ & Not reported \\
\hline $\begin{array}{l}\text { Endogenous } \\
\text { expression }\end{array}$ & Low levels, ubiquitous $(55,96)$ & Low levels, ubiquitous (56) & Low levels, ubiquitous (1) \\
\hline $\begin{array}{l}\text { Subcellular } \\
\text { localization }\end{array}$ & Membrane (predicted) & Membrane (predicted) & $\begin{array}{l}\text { Possibly in nuclear membrane } \\
\text { (1) }\end{array}$ \\
\hline $\begin{array}{l}\text { Genetic } \\
\text { interactors }\end{array}$ & $\begin{array}{l}\text { Function of receptor-like kinase } \\
\text { CR4 depends on Dek1 (7) }\end{array}$ & $\begin{array}{l}\text { Receptor-like kinase ACR4 acts } \\
\text { independent of Dek1 (56) }\end{array}$ & Not reported \\
\hline $\begin{array}{l}\text { Proteolytic } \\
\text { activity }\end{array}$ & $\begin{array}{l}\text { Domains II and III cleave casein } \\
\text { in vitro, stimulated by } \mathrm{Ca}^{2+}(96)\end{array}$ & Not reported & Not reported \\
\hline $\begin{array}{l}\text { Putative } \\
\text { mechanism }\end{array}$ & \multicolumn{3}{|c|}{ May cleave transcription factors in response to signals from the surface of the organism (43) } \\
\hline
\end{tabular}

conserved throughout the plant kingdom and is encoded by a single copy of the gene in each sequenced plant genome (55). The protease domain of DEK1 has proteolytic activity in vitro that can be enhanced by calcium (96). Different models exist for DEK1 function. An initial model proposed a role for maize DEK1 in the release of signals that are perceived by receptor-like kinase CR4, because maize $\mathrm{cr} 4$ mutants share some of the dek1 phenotypes, and cr4/dek1 double mutants show dek1 phenotypes (6). In Arabidopsis, however, Arabidopsis thaliana bomolog of crinkly 4 (acr4)/dek1 double mutants show additive effects, which suggests that dek1 and acr 4 act in different pathways of epidermis specification (43). In another model, DEK1 cleaves homeodomain-leucine zipper IV (HDZipIV) transcription factors, which regulate epidermal cell fate (43). This model is consistent with the cell-autonomous function of DEK1 and the fact that DEK1 carries nuclear targeting signals (1). However, the true subcellular localization of DEK1 remains to be investigated.

\section{Papain-Like Proteases Rcr3 and $\mathrm{NbCathB}$}

Papain-like proteases (family C1, clan CA) contain catalytic residues in the order Cys, His, Asn. As with calpain (family C2, clan CA), the fold consists of two domains (lobes) and the catalytic site lies between them (29). Family $\mathrm{C} 1$ has been subdivided into subfamily C1A, which comprises proteases that contain disulfide bridges and accumulate in vesicles, the vacuole, or the apoplast, and family C1B, which comprises proteases that lack disulfide bridges and are located in the cytoplasm (69). Plants only have C1A proteases. There are approximately 30 papain-like proteases in subfamily C1A encoded by Arabidopsis, subdivided into 8 subfamilies (8). These C1A proteases are produced as preproproteases (Figure $4 a$ ). The autoinhibitory prodomain folds back onto the catalytic site cleft and is removed during the activation of the protease (90). Papain-like proteases are implicated in pathogen perception, disease resistance signaling, defense against insects, and senescence (Table 1).
Suspensor: connection between embryo and endosperm 

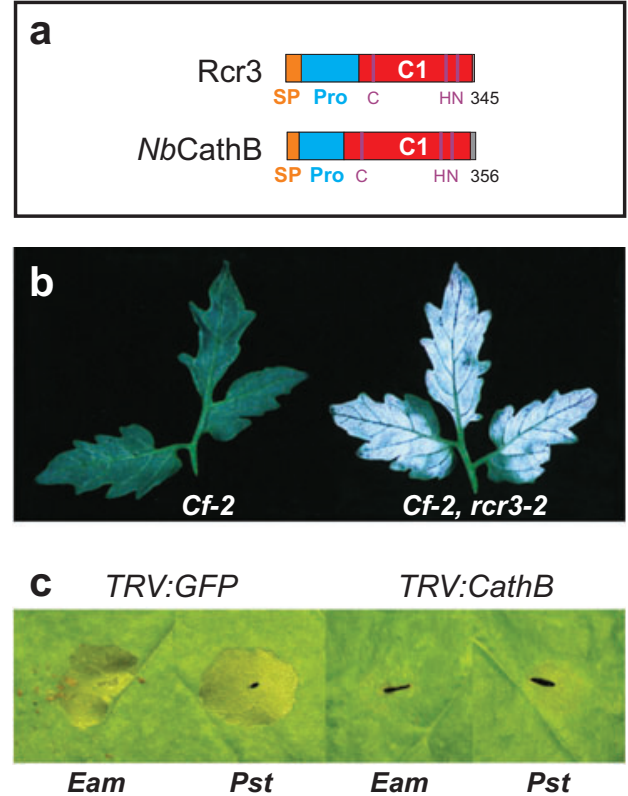

Figure 4

Rcr3 and NbCathB (a) Domains of Rcr3 (required for Cladosporium resistance 3 ) and $\mathrm{NbCathB}$ (Nicotiana benthamiana cathepsin $\mathrm{B}$ ) proteins. SP, signal peptide (orange); pro, autoinhibitory prodomain (blue); C1, protease domain (red); C, H, N, catalytic residues Cys, His, and Asn (purple). (b) Mutant rer3-2 plants have lost Cladosporium fulvum resistance gene-2 (Cf-2)-mediated resistance for the leaf mold fungus Cladosporium fulvum. Reprinted with permission from Reference 24, Copyright 2000, National Academy of Sciences, U. S. A. (c) Silencing of NbCatB suppresses the hypersensitive response induced by the nonhost bacterial pathogens Erwinia amylovora (Eam) and Pseudomonas syringae pv. tomato DC3000 (Pst). Figures kindly provided by Dr. E. Gilroy (Scottish Crop Research Institute, Dundee, Scotland).

Biotrophic: pathogen that feeds on living plant tissues

Hypersensitive response (HR): rapid programmed cell death that occurs at the site of pathogen infection

Nonhost resistance: when all genotypes of a host are resistant against all genotypes of a pathogen
Rcr3. Required for Cladosporium resistance 3 (Rcr3) (Table 3) is essential for the function of the resistance gene $C f-2$ in tomato. The $C f-2$ resistance gene was introgressed from wild tomato plants into cultivated tomato (Lycopersicon esculentum) by plant breeders to generate tomato plants that are resistant to the biotrophic leaf mold fungus Cladosporium fulvum carrying the avirulence gene Avr2. The resistance response involves a hypersensitive response (HR) of cell death at the site of infection, which prevents further pathogen growth. Avr 2 encodes a small, secreted, cysteine-rich protein without obvious homology to other proteins, and $C f-2$ encodes a receptor-like membrane protein
$(25,58) . \operatorname{Rcr} 3$ was identified in a forward genetic screen for $C f-2$ tomato plants that are susceptible to C. fulvum carrying Avr2 (24) (Figure 4b). Rcr3 encodes a secreted papainlike cysteine protease with proven proteolytic activity (49) (Figure 4a). Surprisingly, $C f-2$ plants contain the Rer 3 allele from the wild tomato Lycopersicon pimpinellifolium (Rcr $\left.3^{\text {pim }}\right)$, which differs from the Lycopersicon esculentum allele $\left(\operatorname{Rcr}^{3 e s c}\right)$ in one amino acid deletion and six amino acid substitutions. $R \operatorname{cr} 3^{\text {esc }}$ triggers necrotic responses in combination with $C f-2$, but $R c r 3^{\text {pim }}$ does not (49). This explained a peculiar observation made by plant breeders in the early twentieth century. A necrosis-suppressing gene $(\mathrm{Ne})$, whose identity was unkown, was introgressed from $L$. pimpinellifolium together with $C f-2$ to suppress autonecrotic responses induced by $C f-2 . \mathrm{Ne}$ proved to be $\operatorname{Rer} 3^{\text {pim }}$ (49). Studies of the role of Rcr3 in Avr2 recognition revealed that Avr2 physically interacts with Rcr3 and inhibits its activity (72). Inhibition of Rcr 3 by protease inhibitor E-64 or the absence of Rcr3 activity in rrr 3 mutants cannot trigger the resistance response mediated by Cf- 2 , suggesting that neither the product nor substrates of Rcr3, but the Avr2-Rcr3 complex or a specific conformational change in Rcr3, is required to trigger the resistance response (72). These data are consistent with the guard hypothesis, which predicts that resistance proteins (e.g., Cf-2) are guarding the virulence targets (e.g., Rcr3) of pathogen effector proteins (e.g., Avr2) (72, 91, 92). The upregulation of Rcr3 transcript levels during pathogen infection is consistent with a role in defense (49). However, whether Rcr3 contributes to pathogen resistance and how the Avr2-Rcr3 complex is recognized by Cf-2 remains to be investigated.

NbCatbB. Nicotiana benthamiana Cathepsin $\mathrm{B}$ ( $\mathrm{NbCathB}$ ) (Table 3 ) is required for the HR induced by nonhost pathogens. The potato CatbB transcript level increases early during infection with the oomycete pathogen $\mathrm{Phy}$ tophthora infestans (2). A similar quick transcriptional induction occurs with $N b C a t h B$ in 
Table 3 Papain-like proteases Rcr3 (required for C. fulvum resistance 3) and NbCathB (N. benthamiana Cathepsin B)

\begin{tabular}{|c|c|c|}
\hline Gene name & Rer3 & NbCatbB \\
\hline Described alleles & $\operatorname{rrr} 3-1 \ldots 4(24)$ & None \\
\hline Knockout phenotype & $\begin{array}{l}\text { Loss of resistance for fungus Cladosporium } \\
\text { fulvum carrying Avr2 (24) }\end{array}$ & Not reported \\
\hline Knockdown phenotype & Not reported & Suppresses hypersensitive cell death (35) \\
\hline $\begin{array}{l}\text { Overexpression } \\
\text { phenotype }\end{array}$ & Not reported & Not reported \\
\hline Endogenous expression & $\begin{array}{l}\text { Higher expression in older plants, upregulated } \\
\text { during pathogen infection (49) }\end{array}$ & Induced during hypersensitive cell death $(2,35)$ \\
\hline Subcellular localization & Secreted into leaf apoplast (49) & Secreted (35) \\
\hline Genetic interactors & Requires receptor-like protein Cf-2 (24) & Not reported \\
\hline Proteolytic activity & Degrades casein and gelatin (49) & Not reported \\
\hline Putative mechanism & $\begin{array}{l}\text { May trigger activation of Cf-2-induced } \\
\text { resistance response by complex formation } \\
\text { with fungal inhibitor protein Avr2 (72) }\end{array}$ & $\begin{array}{l}\text { May act in extracellular signaling to regulate } \\
\text { hypersensitive cell death }(35)\end{array}$ \\
\hline
\end{tabular}

N. benthamiana during the HR (35). Virusinduced gene silencing of $N b C a t h B$ prevents the HR induced by two distinct nonhost bacterial pathogens (Figure $4 c$ ). This loss of the $\mathrm{HR}$ is associated with further growth of the bacteria, which indicates that nonhost resistance is hampered. The HR induced by the combined expression of avirulence protein Avr3a with resistance protein R3a was also suppressed in silenced plants, but the HR induced by coexpression of avirulence protein Avr4 and resistance protein Cf- 4 was unaltered (35). This indicates that $N b$ CathB is required for some, but not for all, resistance signaling pathways. $\mathrm{NbCathB}$ is activated during secretion and is also active in noninfected plants. The data indicate that $\mathrm{NbCathB}$ is an extracellular protease that acts in the transduction of signals during recognition of some, but not all, avirulent pathogens. How this protease mediates HR signaling is unknown, but it represents an exciting area for further research.

\section{Deconjugating Enzymes $\mathrm{UCH} 1 / 2$ and ESD4}

The conjugation of ubiquitin and small ubiquitin-like modifiers (SUMO) to lysine residues of target proteins is an important way to regulate the location, activity, and degradation of these proteins (28). Conjugation of ubiquitin and SUMO is mediated by specific E3 ligases, whereas deconjugation is catalyzed by different proteases that belong to MEROPS families C12, C19, and C48. Ubiquitin-specific proteases (UBPs; family C19, clan CA) and ubiquitin C-terminal hydrolases (UCHs; family C12, clan CA) interact with ubiquitin through electrostatic interactions and hydrolyze the bonds formed by the C-terminal glycine of ubiquitin in a highly selective manner, releasing ubiquitin from its precursors or from ubiquitinated proteins. SUMO-deconjugating enzymes (family $\mathrm{C} 48$, clan CE) are specific for the C-terminal glycine of SUMO and release SUMO from both precursors and conjugates. Most C12, $\mathrm{C} 19$, and $\mathrm{C} 48$ proteins are produced in the cytoplasm without a prodomain and move to the nucleus via nuclear localization signals (NLS) (Figure 5a).

Although the C12/C19 and C48 families belong to different clans, the structure of the lobes and the position of the catalytic residues are similar between CA and CE clan proteases. However, the difference between $\mathrm{CA}$ and $\mathrm{CE}$ clan proteases is that the lobes are swapped in the primary sequence, possibly owing to an ancient gene rearrangement 

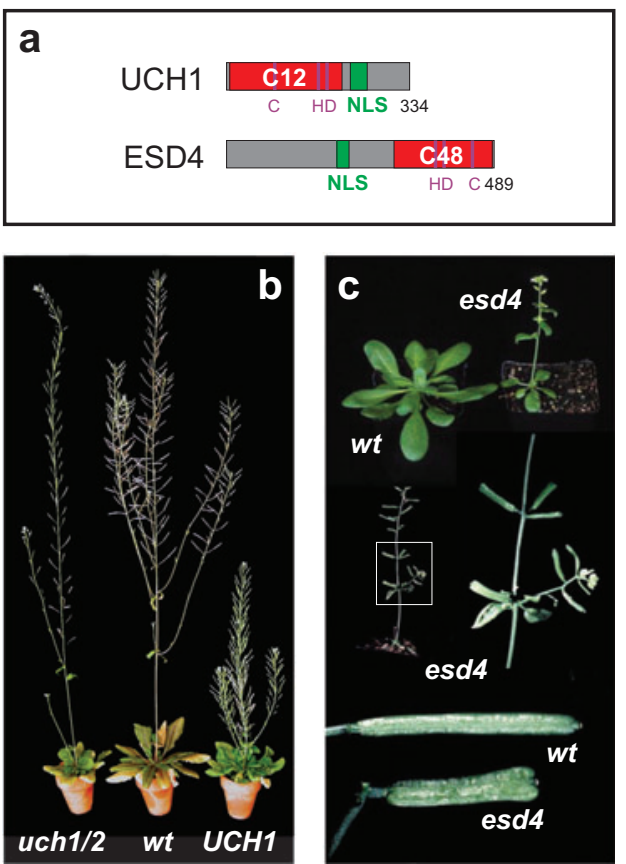

Figure 5

UCH1 and ESD4 (a) Domains of ubiquitin C-terminal hydrolase 1 (UCH1) and early in short days 4 (ESD4) proteins. NLS, nuclear localization signal (green); C12/C48, protease domain (red); C, H, D, catalytic residues Cys, His, and Asn (purple). (b) The uch1-1/uch2-1 double mutant $(u c b 1 / 2)$ shows less branching than wild-type, whereas the UCH1-overexpressing strain shows more branching than wild-type under short day conditions. The picture was kindly provided by Dr. R. Vierstra (University of Wisconsin, Madison). (c) esd4-1 mutant plants flower earlier than wild-type when grown under short day conditions (top). esd4-1 mutants develop siliques at unexpected positions (middle), and siliques are shorter and broader at the tip (bottom). Pictures kindly provided by Dr. N. Elrouby (Max-Planck-Institut für Züchtungsforschung, Cologne, Germany).

$(63,69)$. Members of the C19 family are required for pollen and embryo development $(26,27)$.

$\mathrm{UCH} 1$ and $\mathrm{UCH} 2$. Ubiquitin C-terminal hydrolase 1 and 2 (UCH1 and $\mathrm{UCH} 2$ ) (Table 4) regulate shoot architecture, probably by rescuing specific ubiquitinated proteins from degradation. Among the few UCHs encoded in the Arabidopsis genome, UCH1 and UCH2 share strong sequence similarity and were chosen for functional analysis. Although $u c h 1$ and $u c h 2$ single mutants have no phenotypes, the $u c h 1 / u c h 2$ double mutants show phenotypes that are often the opposite to those observed for $U C H 1$-overexpressing (35S:UCH1) plants (101). Phenotypes in the rosette size, leaf shape, and flower organs were observed, but the strongest phenotype is displayed in the shoot architecture under short day conditions. 35S:UCH1 plants are short bushy plants covered with siliques, whereas uch1/uch2 plants develop a less-branched primary inflorescence when compared with wild-type (101) (Figure 5b). The specific phenotypes suggest that UCHs act on distinct ubiquitinated conjugates. Indeed, UCH2 can release ubiquitin from polyubiquitin precursors and from polyubiquitin conjugates, but the levels of ubiquitin conjugates are unaltered in the 35S:UCH1 and uch1/uch2 plants (101). The phenotypes in shoot architecture suggest a possible link to auxin signaling. The phenotype of the auxin-insensitive mutants axr1-3 and axr2-1 is strongly enhanced by UHC1 overexpression, which indicates that auxin signaling may be affected by $U C H 1 / 2$. Indeed, the stability of an AXR3/IAA17 reporter is stabilized in 35S:UHC1 lines (101). This result leads to the hypothesis that $\mathrm{UCH} 1 / 2$ proteins directly or indirectly rescue auxin/IAA proteins from degradation to dampen auxin signal strength or restore normal plant growth after auxin signaling. In addition, UCH1/2 proteins may also deubiquitinate proteins that are not related to auxin signaling.

ESD4. Early in short days 4 (ESD4) (Table 4) regulates many developmental processes, including flowering time, by modifying the sumoylation status of various proteins. The esd 4 mutant was identified in a screen for mutants that flower earlier in short day conditions. In addition to an earlier flowering time, the esd 4 mutant also has shorter internodes, smaller leaves, altered phylotaxy, fewer solitary flowers, and shorter siliques compared with wild-type (70) (Figure 5c). The early flowering phenotype is partly explained by the fact that transcript levels of the floral repressor FLOWERING LOCUS C (FLC) 
Table 4 Deconjugating enzymes UCH1/2 (ubiquitin C-terminal hydrolase 1/2) and ESD4 (early in short days 4)

\begin{tabular}{|c|c|c|}
\hline Gene name & UCH1/2 & ESD4 \\
\hline Described alleles & $u c b 1-1, u c b 2-1$ (101) & esd $4-1,2(64,70)$ \\
\hline Knockout phenotype & $\begin{array}{l}\text { Shorter petioles, smaller leaves, deformed petals, } \\
\text { large stigmas, less fertile, less branched (101) }\end{array}$ & $\begin{array}{l}\text { Early flowering in short days, smaller leaves, } \\
\text { shorter internodes and siliques, altered } \\
\text { phylotaxy, fewer leaves and flowers }(64,70)\end{array}$ \\
\hline Knockdown phenotype & Not reported & Not reported \\
\hline $\begin{array}{l}\text { Overexpression } \\
\text { phenotype }\end{array}$ & $\begin{array}{l}\text { Shorter petioles, smaller leaves, bushy plants } \\
\text { covered with siliques (101) }\end{array}$ & No phenotype (64) \\
\hline $\begin{array}{l}\text { Endogenous } \\
\text { expression }\end{array}$ & Ubiquitous (101) & Ubiquitous (64) \\
\hline Subcellular localization & Nuclear and cytoplasmic (UCH1/2-GFP) (101) & $\begin{array}{l}\text { Inner surface of nuclear envelope (ESD4-GFP) } \\
\text { (64) }\end{array}$ \\
\hline Genetic interactors & $\begin{array}{l}\text { UCH1 overexpression enhances } \operatorname{axr} 1 / 2 \text { auxin } \\
\text { mutant phenotypes (101) }\end{array}$ & $\begin{array}{l}\text { In same pathway as nuclear pore anchor NUA } \\
(99)\end{array}$ \\
\hline Proteolytic activity & $\begin{array}{l}\text { Cleaves ubiquitin from polyubiquitin and from } \\
\text { ubiquitin conjugates (101) }\end{array}$ & $\begin{array}{l}\text { Cleaves } A t \text { SUMO1/2 from its precursor and } \\
\text { from conjugates }(20,64)\end{array}$ \\
\hline Putative mechanism & $\begin{array}{l}\text { May rescue specific ubiquitin-tagged proteins } \\
\text { (e.g., AXR3) from degradation (101) }\end{array}$ & $\begin{array}{l}\text { Regulates sumoylation status of different } \\
\text { proteins involved in diverse developmental } \\
\text { processes (64) }\end{array}$ \\
\hline
\end{tabular}

are reduced in esd 4 mutants, which causes an upregulation of the flowering time genes SUPPRESSOR OF OVEREXPRESSION OF CONSTANS 1 (SOC1) and FLOWERING LOCUS T (FT) (70). However, analysis of fc/esd4 double mutants indicated that ESD4 also regulates flowering time genes independently of FLC (70). ESD4 encodes a desumoylating enzyme that can cleave certain Arabidopsis SUMO proteins from their precursor and from conjugates $(20,64)$. Consistent with the presumed role of ESD4 in desumoylating other proteins, SUMO conjugates accumulate in esd4 mutants, and SUMO overexpression in esd4 plants further enhances the accumulation of SUMO conjugates and the esd4 mutant phenotype (64). ESD4 proteins localize to the inner surface of the nuclear envelope (64) and physically interact with a nuclear pore anchor (NUA) (99). nua mutants phenocopy esd 4 mutants and nua/esd 4 double mutants are indistinguishable from single mutants, which suggests that both genes act in the same pathway (99). Interestingly, besides an increased level of SUMO conjugates and a reduced FLC transcript level, nua mutants accumulate more mRNA in the nucleus, consistent with the role of NUA proteins as determined in yeast (99). Given the spectrum of different phenotypes of esd4 mutants and the range of proteins that are regulated by sumoylation, ESD4 probably acts in multiple pathways to desumoylate different substrates, each involved in different processes, including flowering time.

\section{Caspase-Like Proteases MCAs and VPEs}

Caspases (family C14, clan CD) have been intensively investigated in animals because they regulate apoptotic cell death (73). Their fame is also a source of confusion because the hunt for caspase activities (cleavage after Asp) in plants resulted in the description of many "caspase-like proteases" that are probably not related to caspases (93). In this review, caspase-like proteases are defined as sharing sequence homology or at least structural homology to the animal caspases. Proteases that share sequence homology with animal caspases are absent from plant
Apoptotic cell death: a form of programmed cell death in animals

Caspase: cysteine protease that cleaves substrates after aspartic acid residues 

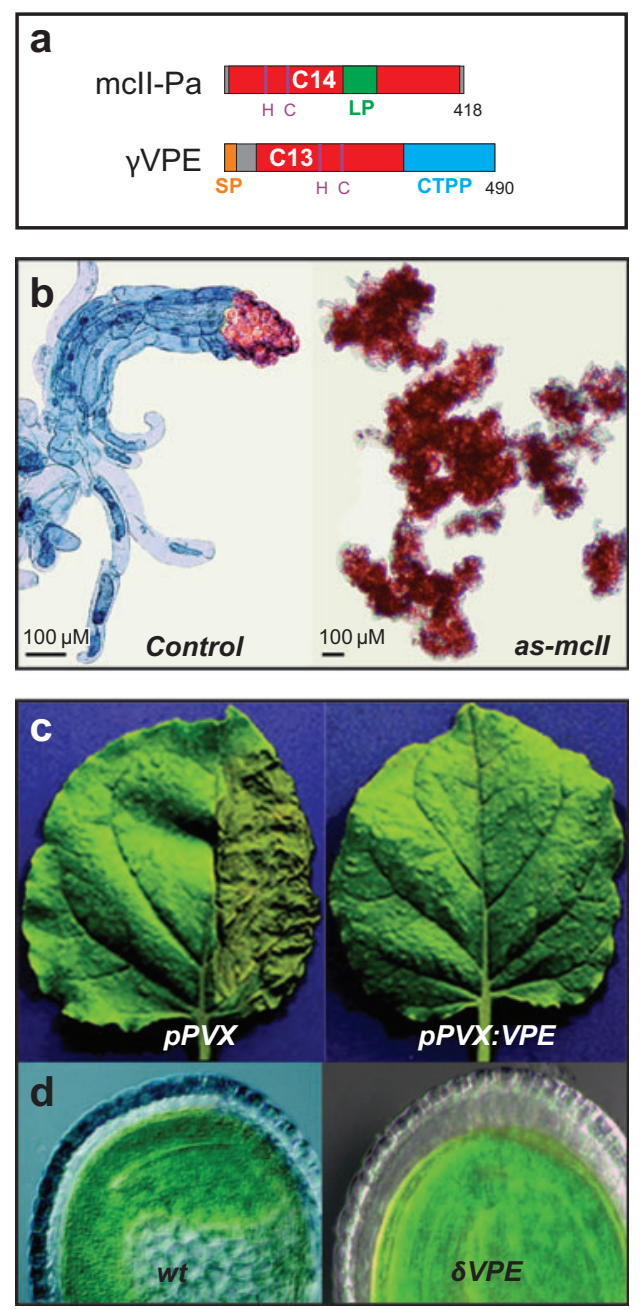

Figure 6

mcII-Pa and VPE (a) Domains of metacaspase type II of Picea abies (mcII-Pa) and $\gamma$ vacuolar processing enzymes $(\gamma \mathrm{VPE})$ proteins. SP, signal peptide (orange); CTPP, autoinhibitory C-terminal propeptide (blue); C13/C14, protease domain (red); H, C, catalytic residues His and Cys (purple); LP, linker peptide (green). (b) Silencing of mcII-Pa prevents cell death induced during somatic embryogenesis, visualized by staining with acetocarmine (red, viable cells) and Evans blue (blue, dead cells). Picture kindly provided by Dr. P. Bozhkov (Sveriges Lantbruksuniversitet, Uppsala, Sweden). (c) NbVPE silencing blocks the hypersensitive response (HR), cell death induced by tobacco mosaic virus (TMV), in plants containing the $N$ resistance gene. Collapsed tissue is visible $24 \mathrm{~h}$ after triggering HR. Reprinted from Reference 45 with permission from the American Association for the Advancement of Science. $(d)$ Cell death in two cell layers during seed coat formation is delayed in $\Delta$ vpe mutants. Reprinted from Reference 65 with permission from the American Society of Plant Biologists. genomes, but plants do contain metacaspases (MCAs; family C14) and vacuolar processing enzymes (VPEs; family C13). These caspaselike enzymes are unified in clan CD and use a catalytic Cys that is activated by the catalytic His for nucleophilic attack. Caspase-like enzymes are folded as an $\alpha / \beta / \alpha$ sandwich (17). Clan CD proteases are highly selective for cleavage after specific residues: Asp for animal caspases, Arg for MCAs, and Asn for VPEs (69). Most CD clan proteases are produced with $\mathrm{N}$ - and $\mathrm{C}$-terminal propeptides (Figure 6a). Caspases and MCAs (family C14) are usually cytoplasmic or nuclear, whereas VPEs (family C13) are located in vesicles or in the vacuole. (Meta)caspases are produced with a linker protein that is proteolytically removed, which results in a heterocomplex of a p20 chain and a p10 chain (Figure $6 \boldsymbol{a}$ ). Given the evolutionary relationship with caspases, caspase-like enzymes in plants have long been suspected to regulate PCD. Published work from the past few years indicates that this is indeed the case (summarized below).

mcII-Pa. Metacaspase type II of Picea abies (mcII-Pa) (Table 5) mediates PCD during somatic embryogenesis in Norway spruce (Picea abies). Somatic embryogenesis of Norway spruce is an elegant system in which to study embryogenesis because embryo development can be synchronized by changing the hormone balance, and the embryos have large suspensor cells that undergo gradual, successive PCD (11). The fact that this PCD is accompanied by caspase activity and can be inhibited by a caspase inhibitor led to the identification of $m c I I-P a$, a metacaspase that is specifically expressed in suspensor cells that undergo PCD (84). Silencing mcII-Pa prevents PCD and suppresses caspase activity and the frequency of nuclear degradation (84) (Figure 6b). However, biochemical characterization of the mcII-Pa protein revealed that it cleaves after Arg but not after Asp, which suggests that the caspase activity is not caused by mcII-Pa activity, but by enzymes activated by mcII-Pa. Interestingly, mcII-Pa 
Table 5 Caspase-like proteases mcII-Pa (metacaspase type II of Picea abies) and VPE (vacuolar processing enzyme)

\begin{tabular}{|c|c|c|}
\hline Gene name & $m c I I-P a$ & $V P E$ \\
\hline Described alleles & None & 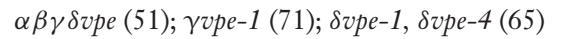 \\
\hline \multirow[t]{3}{*}{ Knockout phenotype } & \multirow[t]{3}{*}{ Not reported } & $\alpha \beta \gamma \delta v p e:$ abolished toxin-induced cell death (51) \\
\hline & & rvpe: slightly decreased pathogen resistance (71) \\
\hline & & $\begin{array}{l}\text { Svpe: delayed cell death during seed coat } \\
\text { development }(65)\end{array}$ \\
\hline $\begin{array}{l}\text { Knockdown } \\
\text { phenotype }\end{array}$ & $\begin{array}{l}\text { No cell death in somatic embryos, no embryonic } \\
\text { pattern formation }(84)\end{array}$ & $\begin{array}{l}\text { NbVPE: blocks virus-induced hypersensitive cell } \\
\text { death (38) }\end{array}$ \\
\hline $\begin{array}{l}\text { Overexpression } \\
\text { phenotype }\end{array}$ & Not reported & Not reported \\
\hline \multirow[t]{2}{*}{$\begin{array}{l}\text { Endogenous } \\
\text { expression }\end{array}$} & \multirow[t]{2}{*}{$\begin{array}{l}\text { Only in somatic embryo cells that are committed } \\
\text { to cell death and in procambial strands that lead } \\
\text { to xylem differentiation ( } 84)\end{array}$} & $\begin{array}{l}\text { NbVPE: upregulated during hypersensitive cell } \\
\text { death (38) }\end{array}$ \\
\hline & & $\begin{array}{l}\gamma V P E: \text { upregulated during programmed cell } \\
\text { death (PCD) and pathogen infection }(51,71) \\
\delta V P E: \text { only in maternal cell layers during seed } \\
\text { development }(65)\end{array}$ \\
\hline $\begin{array}{l}\text { Subcellular } \\
\text { localization }\end{array}$ & $\begin{array}{l}\text { Cytoplasmic and nuclear (immunolocalization) } \\
(12)\end{array}$ & In vacuole and vesicles (immunolocalization) (27) \\
\hline Genetic interactors & Not reported & Not reported \\
\hline Proteolytic activity & Cleaves after Arg, but not after Asp in vitro (12) & Cleaves after Asn (48) \\
\hline Putative mechanism & $\begin{array}{l}\text { May cleave nuclear structural proteins to } \\
\text { disassemble the nuclear envelope during PCD } \\
\text { (12) }\end{array}$ & $\begin{array}{l}\text { May activate vacuolar enzymes and disintegrate } \\
\text { the vacuolar membrane to release hydrolytic } \\
\text { enzymes during PCD }(37,38,51,65)\end{array}$ \\
\hline
\end{tabular}

translocates from the cytoplasm into the nucleus during PCD and associates with chromatin and disassembling nuclear pore complexes (12). Nuclear disintegration can be induced by adding mcII-Pa protein to nuclei isolated from PCD-deficient cell lines (12). This nuclear disintegration can be inhibited by a mcII-Pa inhibitor and is absent if a catalytic mutant of mcII-Pa is added instead (12). The data lead to a hypothesis in which cytoplasmic metacaspases participate in PCD by degrading the nuclear envelope, which leads to nuclear degradation (12).

VPEs. Vacuolar processing enzymes (VPEs) (Table 5) are essential for PCD induced during disease resistance responses, by a fungal toxin, and during seed coat development. VPEs were initially studied for their role in the maturation of seed storage proteins, but the upregulation of these genes during different kinds of PCD prompted further phenotype investigation. Silencing of VPEs in N. benthamiana abolishes the hypersensitive cell death triggered by tobacco mosaic virus (TMV) in plants carrying the TMV-resistance gene $N$ (38) (Figure 6c). Cytological studies revealed that vacuolar collapse precedes PCD and both are prevented in VPE-silenced plants (38). Arabidopsis has four VPEs: $\alpha, \beta$, $\gamma$, and $\delta . \delta V P E$ is expressed specifically in two cell layers of the maternal inner integument of developing seed coats (65). These cell layers normally undergo PCD early during seed development, which results in the degradation of nuclei and shrinkage of the inner integument. However, this PCD is absent in $\delta v p e$ mutants, although the final seed coat is normal (Figure $6 \boldsymbol{d}$ ). In contrast to $\delta V P E$, the $\gamma V P E$ gene is expressed throughout the plant, and $\gamma$ ope mutant plants show a weak reduced resistance toward various pathogens
Metacaspases: proteases that share certain conserved sequence motifs with caspases

Integument: covering of an organ, in this case a seed 
(71). Arabidopsis mutants lacking all four VPE genes $(\alpha \beta \gamma \delta v p e)$ are insensitive to cell death induced by the fungal toxin Fumonisin B1 (FB1) (51). Of the single mutants, only rope shows a delayed FB1-induced cell death, which suggests that $V P E$ genes act redundantly and that $\gamma V P E$ makes the largest contribution to FB1-induced PCD in leaves (51). VPE proteases act on caspase substrates and are inhibited by caspase inhibitors, which indicates that VPEs are the plant functional orthologs of animal caspases $(38,51,65,71)$. The mechanism of how VPEs act in PCD is unknown, but their location, and therefore probably their signaling role, is distinct from
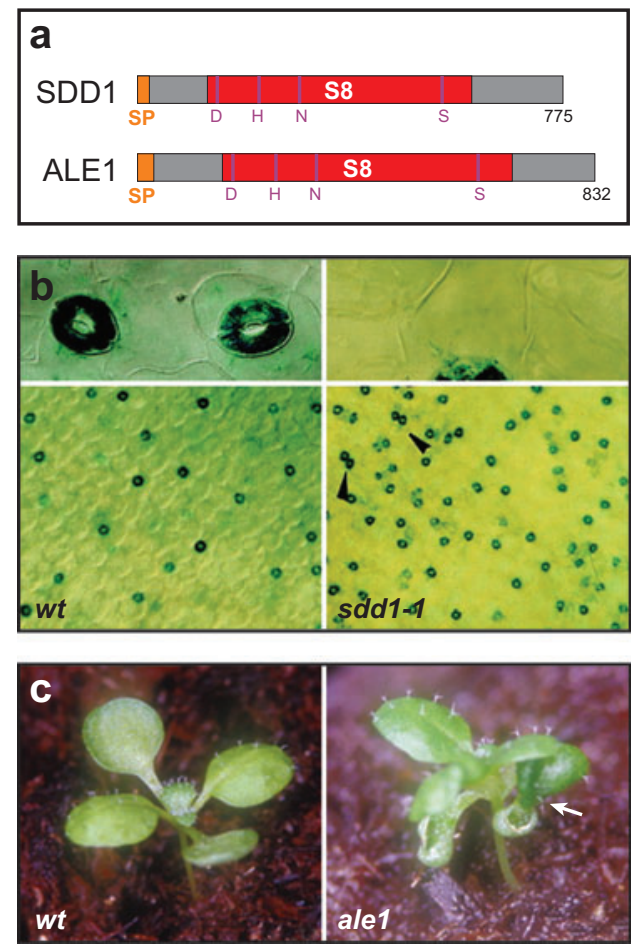

Figure 7

SDD1 and ALE1 (a) Domains of stomatal density and distribution 1 (SDD1) and abnormal leaf shape 1 (ALE1) proteins. SP, signal peptide (orange); S8, protease domain (red); D, H, N, S, catalytic residues Asp, His, and Ser (purple). (b) sdd1-1 mutants have fourfold more stomata and stomata clusters than wild-type. Reprinted with permission from Reference 9, Copyright 2000, Cold Spring Harbor Laboratory Press. (c) 16-day-old seedlings of ale1-1 have fused cotyledons that lack a cuticle (arrow). Reprinted from Reference 88 with permission from the Company of Biologists. that of animal caspases. VPEs may activate vacuolar enzymes, which may trigger the collapse of the vacuolar membrane, resulting in the disintegration of cellular structures by released hydrolytic enzymes.

\section{SERINE PROTEASES}

Serine proteases use the active site Ser as a nucleophile. The catalytic mechanism is very similar to that of cysteine proteases, and some serine proteases are even evolutionarily related to cysteine proteases. With more than 200 members, serine proteases are the largest class of proteolytic enzymes in plants. Plant serine proteases are divided into 14 families. These families belong to 9 clans that are evolutionarily unrelated to each other. Families S8, S9, S10, and S33 are the largest serine protease families in plants, with each containing approximately 60 members. Biological functions for serine proteases have been described for some of the subtilases (SDD1 and ALE1; family S8, clan SB), carboxypeptidases (BRS1 and SNG1/2; family S10, clan SC), and plastid-localized members of the S1, S26, and S14 families (DegPs, Plsp1, and ClpPs; Table 1).

\section{Subtilisin-Like Proteases SDD1 and ALE1}

Subtilases (family S8, clan SB) contain a catalytic triad in the order Asp, His, Ser, and are folded as a seven-stranded $\beta$-sheet, sandwiched between two layers of helices. Subtilases are encoded as preproproteins and are usually secreted and processed at both the $\mathrm{N}$ and $\mathrm{C}$ terminus (68) (Figure 7a). Most subtilases are endopeptidases. Some subtilases are expected to have a broad substrate range, others are considered to be specific prohormone convertases. The Arabidopsis genome encodes approximately 70 subtilases, which can be divided into three subfamilies (8). A biological role is known for only two Arabidopsis subtilases (see below). However, no macroscopic phenotypes were observed for 
Table 6 Subtilisin-like proteases SDD1 (stomatal density and distribution 1) and ALE1 (abnormal leaf shape 1)

\begin{tabular}{l|l|l}
\hline Gene name & \multicolumn{1}{|c}{ SDD1 } & \multicolumn{1}{c}{ ALE1 } \\
\hline Described alleles & sdd1-1 (9) & ale1-1, ale1-2 (88) \\
\hline Knockout phenotype & More stomata, also in clusters (9) & Embryo lacks cuticle (88) \\
\hline Knockdown phenotype & Not reported & Not reported \\
\hline Overexpression phenotype & $2-3$-fold decrease in stomata (95) & Not reported \\
\hline Endogenous expression & Only in guard mother cells (95) & Only in endosperm, not in seedling (88) \\
\hline Subcellular localization & $\begin{array}{l}\text { Secreted (predicted) truncated SDD1-GFP } \\
\text { in the plasma membrane (95) }\end{array}$ & Secreted (predicted) \\
\hline Genetic interactors & $\begin{array}{l}\text { Overexpression phenotype depends on } \\
\text { receptor-like protein TMM (too many } \\
\text { mouths) (95) }\end{array}$ & $\begin{array}{l}\text { Acts independently of receptor-like kinases } \\
\text { ACR4 (Arabidopsis thaliana homolog of } \\
\text { crinkly 4) and ALE2 (Abnormal leaf shape 2) } \\
\text { (88, 97) }\end{array}$ \\
\hline Putative mechanism & $\begin{array}{l}\text { Not reported } \\
\text { to suppress the development of neighboring } \\
\text { stomata (95) }\end{array}$ & $\begin{array}{l}\text { Could activate signals or enzymes from the } \\
\text { endosperm to stimulate cuticle formation on } \\
\text { the embryo surface (88) }\end{array}$ \\
\hline
\end{tabular}

knockout lines of 55 other subtilases, which indicates that these proteases act redundantly or have condition-specific roles (68).

SDD1. Stomatal density and distribution 1 (SDD1) (Table 6) specifically regulates the position of stomata development within the epidermis. The $s d d 1-1$ mutant was identified in a forward genetic screen for mutants with an altered stomatal density and distribution (9). The number of stomata in $s d d 1-1 \mathrm{mu}-$ tants is two- to fourfold higher than wild-type in all aerial organs except for the cotyledons (Figure 7b). Many stomata are also clustered and almost every epidermal cell is in contact with at least one guard cell. No other morphological alterations are observed in $s d d 1-1$ mutant plants, consistent with the specific expression of the SDD1 gene: Transcripts are only detectable in guard mother cells during guard cell development (95). The SDD1 gene encodes an S8 subtilisin-like serine protease (9) (Figure 7a). The SDD1 protein is expected to be secreted, but localization studies with SDD1-GFP fusion proteins failed because subtilases are proteolytically processed at both the $\mathrm{N}$ and $\mathrm{C}$ terminus. A GFP fusion with a truncated SDD1 localizes to the plasma membrane, but it is unknown if this trun- cated fusion protein complements the $s d d 1-$ 1 phenotype (95). Overexpression of SDD1 results in a two- to threefold reduction in stomatal density in wild-type plants, and is accompanied by the formation of stomata that are arrested before the division into the two guard cells (95). SDD1 overexpression does not change the increased number of stomata caused by a mutation in receptor-like protein TMM (too many mouths), which indicates that SDD1 acts upstream of TMM in the same signaling pathway (95). Although SDD1 remains to be investigated biochemically, the data are consistent with the model that SDD1 is localized at the plasma membrane of developing stomata mother cells and generates signals that move to neighboring cells to prevent the formation of nearby stomata, either by inhibiting the development of stomata or by promoting differentiation into epidermal cells (95). TMM may act as a receptor of this signal (95).

ALE1. Abnormal leaf shape 1 (ALE1) (Table 6) is responsible for cuticle development during embryogenesis. ale1 mutants were identified during a forward genetic screen because they have an obvious phenotype: ale 1 seedlings die within three days after 
germination in open air but they survive at high relative humidity, which suggests that the lethality is caused by water loss (88). Mutant ale1 plants produce small, crinkled cotyledons and leaves that are often fused to each other (Figure 7c). Once beyond the seedling stage, ale1 mutants develop normally. Electron microscopy reveals that no cuticle is formed on ale 1 embryos, and that the endosperm remains attached to the embryo tissue (88). The lack
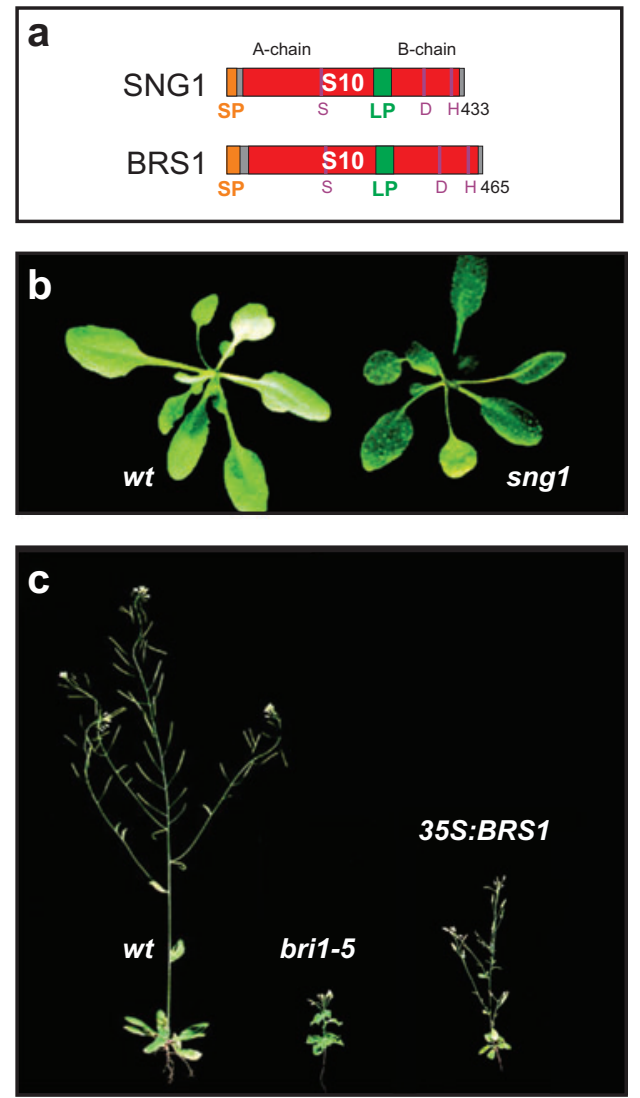

Figure 8

SNG1 and BRS1 (a) Domains of sinapoylglucose accumulator 1 (SNG1) and brassinosteroid insensitive 1 suppressor 1 (BRS1) proteins. SP, signal peptide (orange); LP, linker peptide (green); S10, protease domain (red); S, D, H catalytic residues Ser, Asp, His (purple). (b) sng1 mutants are less fluorescent than wild-type under UV light because they do not accumulate the UV protectant compound sinapoylmalate. Reprinted from Reference 52 with permission of copyright holder, American Society of Plant Biologists. (c) BRS1 overexpression suppresses the dwarfing caused by the bri1-5 allele. Reprinted with permission from Reference 54, Copyright 2001, National Academy of Sciences, U. S. A. of a cuticle in ale 1 mutant embryos explains the crinkled and fused cotyledons and excessive water loss, which causes seedling lethality. Interestingly, the $A L E 1$ gene is expressed only in the endosperm and not in the embryo or the seedling, which suggests that the endosperm plays a role in the formation of the cuticle of the embryo (88). The ALE1 gene encodes a S8 subtilisin-like serine protease (88) (Figure 7a). The biochemical properties and subcellular location of the ALE1 protein remain to be characterized, but ALE1 is predicted to be secreted and proteolytically active (88). ale 1 phenotypes are similar to phenotypes caused by mutations in the receptorlike kinases ACR4 and ALE2. However, acr4 and ale 2 mutant alleles act synergistically with ale1, which indicates that ALE1 has a different mode of action $(89,97)$. The data suggest that the ALE1 protein is secreted by the endosperm and promotes cuticle formation on the embryo, e.g., by proteolytically activating enzymes involved in cuticle deposition (88).

\section{Carboxypeptidase-Like Proteases SNG1/2 and BRS1}

Serine carboxypeptidase protease-like proteins (SCPLs; family S10, clan SC) contain a catalytic triad in the primary sequence order Ser, Asp, His and fold as an $\alpha / \beta$ hydrolase, which is common to many other hydrolytic enzymes. SCPLs are distinct from other serine proteases in that they are active only at acidic $\mathrm{pH}$. SCPLs are produced as preproproteases and often accumulate in the vacuole (Figure 8a). Posttranslational removal of an internal linker peptide results in a disulfide-linked heterocomplex of A- and B-chains (Figure 8a). There are nearly 60 SCPLs in the Arabidopsis genome, divided into different major subfamilies (32). Biological functions have been described for three SCPLs that belong to two different subfamilies. These proteins display a striking variety not only in phenotypes, but also especially in the reactions they catalyze. 
Table 7 Carboxypeptidase-like proteins SNG1/2 (sinapoylglucose accumulator 1/2) and BRS1 [brassinosteroid insensitive 1 (BRI1) suppressor 1]

\begin{tabular}{l|l|l}
\hline $\begin{array}{l}\text { Gene name } \\
\text { Described alleles }\end{array}$ & \multicolumn{1}{|c}{ SNG1; SNG2 } & \multicolumn{1}{c}{ BRS1 } \\
\hline Knockout phenotype & sng1: less fluorescence of leaves under UV (52) & No phenotype (54) \\
\hline $\begin{array}{l}\text { Knockdown phenotype } \\
\text { phenexpression }\end{array}$ & Not reported & Not reported \\
\hline Endogenous expression & $\begin{array}{l}\text { Not reported } \\
\text { SNG1: in all organs (32) }\end{array}$ & Suppression of bri1-5 phenotype (54) \\
\hline Subcellular localization & Vacuolar (predicted) & $\begin{array}{l}\text { Ubiquitous, overlaps with BRI1 expression } \\
\text { (106) }\end{array}$ \\
\hline Genetic interactors & Not reported & $\begin{array}{l}\text { Secreted (predicted) BRS1-GFP is in the } \\
\text { cell wall (106) }\end{array}$ \\
\hline Proteolytic activity & $\begin{array}{l}\text { No carboxypeptidase activity observed for either } \\
\text { SNG1 (52) or SNG2 (81, 82) }\end{array}$ & $\begin{array}{l}\text { Suppresses phenotypes only of weak bri1 } \\
\text { alleles, not of strong bri1 alleles or } \text { er } \\
\text { (erecta) and clv1 (clavata 1) mutants (54) }\end{array}$ \\
\hline $\begin{array}{l}\text { Putative mechanism } \\
\text { dipeptides (106) }\end{array}$ \\
\hline $\begin{array}{l}\text { Catalyzes the transacylation of sinypolyesters via } \\
\text { the use of sinapoylglucose as donor and malate } \\
\text { (SNG1) or choline (SNG2) as acceptor (52, 82) }\end{array}$ & $\begin{array}{l}\text { Could remove proteins that block } \\
\text { brassinosteroid (BR) perception or } \\
\text { activate proteins required for BR } \\
\text { perception (106) }\end{array}$ \\
\hline
\end{tabular}

SNG1 and SNG2. Sinapoylglucose accumulator 1 and 2 (SNG1 and SNG2) (Table 7) are SCPLs that act as acyltransferases in the biosynthesis of sinapoyl esters, which provide UV-B protection $(52,57,82)$. Leaves of Arabidopsis sng1 mutants are less fluorescent under UV light, lack sinapoylmalate, and accumulate the donor molecule, sinapoylglucose $(52,57)$ (Figure $8 b$ ). Similarly, seeds of $s n g 2$ mutants lack sinypoylcholine and accumulate choline (81). The identification of the proteins encoded by $S N G 1$ and $S N G 2$ was surprising. Heterologous expression of the SNG1 and SNG2 proteins demonstrated that they catalyze the acyltransferase reaction but lack carboxypeptidase activity $(52,81,82)$. SNG1 and SNG2 belong to a plant-specific clade of SCPL proteins that also includes 19 other Arabidopsis SCPLs and a tomato glucose acyltransferase (53), but not BRS1 (see below) (32). This suggests that this clade of SCPLs contains more acyltransferases that may contribute to the diversity of secondary metabolites in plants (32).
BRS1. Bri1 suppressor 1 (BRS1) (Table 7) contributes to the perception of brassinosteroid (BR) growth hormone, although phenotypes are observed only by overexpression analysis in a bri1 mutant background. Receptor-like kinase BRI1 (BR insensitive 1) is essential for the perception of BR, and reduced BR perception in bri1 mutants leads to a dwarfed phenotype. BRS1 was identified from an activation tagging screen for suppressors of bri1-5, a weak mutant allele of BRI1 (54) (Figure 8c). Overexpression of BRS1 leads to suppression of the dwarf phenotype of bri15 mutant plants, but not of kinase-dead mutant bri1 alleles (54). The phenotype is specific because BRS1 overexpression does not cause phenotypes in wild-type plants and can not suppress phenotypes caused by mutations in the receptor-like kinases clavata-1 (CLV1) and erecta (ER) (54). No phenotypes are observed in $b r s 1$ knockout lines, which indicates that BRS1 homologs act redundantly (54). Overexpression of a catalytic mutant of BRS1 could not suppress the bri1-5 phenotype, which 
indicates that catalytic activity is required for BRS1 function (54). BRS1 was characterized biochemically after purification from Arabidopsis plants overexpressing BRS1 (106). As with other S10 enzymes, BRS1 activation involves the posttranslational removal of a linker peptide, which results in A- and B-chains that remain linked through disulfide bridges. This activation step requires BRS1 activity because active site BRS1 mutants accumulate as proproteins. Active BRS1 can cleave
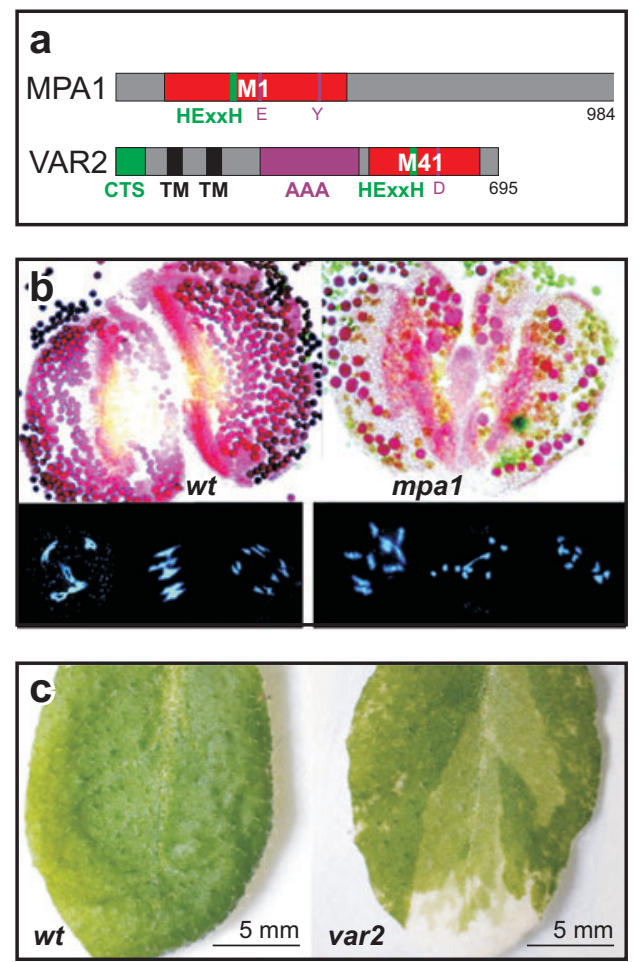

Figure 9

MPA1 and VAR1/2 (a) Domains of meiotic prophase aminopeptidase 1 (MPA1) and yellow variegated 1 (VAR1) proteins. CTS, chloroplast targeting sequence (green); TM, transmembrane domain (black); AAA, ATP-binding cassette (purple); M1/M41, protease domain (red); E, Y, D, catalytic residues Glu, Tyr, and Asp (purple); HExxH, zinc-binding motif (green). (b) The top panel shows that mpa1 mutants have nonviable pollen (green). The bottom panel shows that during meiosis (diakinesis, metaphase I, anaphase I), chromosomes do not pair during metaphase I in the mpa1 mutants, which leads to unequal division of the chromosomes. Reprinted from Reference 78 with permission from the American Society of Plant Biologists. (c) var 2 mutant lacks developed chloroplasts in the white sectors. Reprinted from Reference 47 with permission from the American Society of Plant Biologists. synthetic dipeptides in vitro, which is significant because other S10 family members, such as SNG1 (see above), act as acyltransferases, rather than proteases. A role for endogenous $B R S 1$ in wild-type plants remains to be shown, but its expression pattern is ubiquitous and overlaps with that of BRI1, and BRS1-GFP fusion proteins are detected in the cell wall, which is different from most SCPLs (106). These details and the genetic data are consistent with the model that BRS1 acts upstream of BRI1 in BR signaling, either by activating proteins that assist in $\mathrm{BR}$ perception, or by removing proteins that block the BR binding site.

\section{METALLOPROTEASES}

Metalloproteases contain catalytic metal ions that activate water for nucleophilic attack while stabilizing the oxyanion hole. Plant genomes encode approximately 100 metalloproteases that belong to 19 families. These families are diverse and are divided over 11 clans that are evolutionarily unrelated. Plant metalloprotease families usually contain fewer than 20 members. Metalloproteases are involved in nodulation, plastid differentiation, thermotolerance, regulation of root and shoot meristem size, sensitivity to auxin conjugates, and meiosis (Table 1). Four of these proteases are discussed below.

\section{Clan MA Metalloproteases MPA1 and VAR1/2}

Clan MA metalloproteases are united by the presence of a HExxH motif in which the two His $(\mathrm{H})$ residues are ligands of a single zinc ion, and the Glu (E) provides a catalytic function (Figure 9a). These proteases are folded as a bundle of helices and a $\beta$-sheet, and the active site is between two helices. In plants, clan MA contains six protease families. Members of the M1 family are mostly aminopeptidases, whereas family M41 members act progressively from both the $\mathrm{N}$ and $\mathrm{C}$ terminus. M41 proteases share homology with the 
Table 8 Clan MA metalloproteases MPA1 (meiotic prophase aminopeptidase 1) and VAR1/2 (yellow variegated 1/2)

\begin{tabular}{|c|c|c|}
\hline Gene name & MPA1 & VAR2 \\
\hline Described alleles & mpa1 (78) & $\operatorname{var} 2-1 \ldots 8(18,19,60,87)$ \\
\hline Knockout phenotype & $\begin{array}{l}\text { Impaired meiosis, reduced fertility, } \\
\text { suppressed recombination }(78)\end{array}$ & $\begin{array}{l}\text { Variegation: white sectors in all tissues, except } \\
\text { cotyledons }(19,60)\end{array}$ \\
\hline Knockdown phenotype & Not reported & Not reported \\
\hline $\begin{array}{l}\text { Overexpression } \\
\text { phenotype }\end{array}$ & Not reported & No phenotype (103) \\
\hline Endogenous expression & Reproductive and vegetative tissues (78) & All green tissues (102) \\
\hline Subcellular localization & Cytoplasm and nucleus (78) & Thylakoid membrane (18) \\
\hline Genetic interactors & Not reported & $\begin{array}{l}\text { var2 phenotype is suppressed by fug } 1 ; s c o 1 ; c p l c 2 \text { and } \\
\text { overexpression of FtsH } 8(61,66,102)\end{array}$ \\
\hline Proteolytic activity & Not reported & Not reported \\
\hline Putative mechanism & $\begin{array}{l}\text { May regulate complex assembly and } \\
\text { disassembly required for chromosome } \\
\text { pairing during prophase I of meiosis (78) }\end{array}$ & $\begin{array}{l}\text { Dual: removes photodamaged D1 protein from } \\
\text { photosystem II (3) and regulates thylakoid } \\
\text { formation during chloroplast biogenesis (18) }\end{array}$ \\
\hline
\end{tabular}

well-studied FtsH protease of Escherichia coli. FtsH proteases are membrane-bound, contain two transmembrane domains, and show ATPdependent proteolytic activity.

MPA1. Meiotic prophase aminopeptidase 1 (MPA1) (Table 8) is essential for chromosome pairing and recombination during meiosis. mpa1 mutants were identified from a forward genetic screen for mutants with reduced fertility (78). Siliques of mpa1 mutants are smaller and contain only two or three seeds. A large proportion of mpa1 pollen is not viable, smaller than wild-type, and deformed. Cytological analysis reveals that meiosis is impaired in both male and female gametogenesis (78). Homologous chromosomes fail to pair at the end of prophase I and the chromosomes separate unequally between the daughter cells (Figure $\mathbf{9 b}$ ). Homologous recombination is significantly repressed and only a few nuclei contain the proper five chromosomes by the end of anaphase II. MPA1 encodes a metalloprotease of a M1 subfamily that is sensitive to the antibiotic purimycin and the noncompetitive fluorescent inhibitor DAMPAQ-22. Adding these inhibitors to wild-type plants can phenocopy the mpal phenotype (78). Detailed immunolocalization studies with meiotic marker proteins indicate that the win- dow of MPA1 activity occurs at an early stage in the recombination pathway, soon after the RecA homolog RAD51 is loaded onto the chromatin, but before loading of the mismatch repair protein MSH4 (78). These data indicate that MPA1 may be required for the assembly or disassembly of protein complexes that contain RAD51 or MSH4. MPA1 is also expressed in vegetative tissue, but its function there is unknown because mpa1 plants grow normally.

VAR2. Yellow variegated 2(VAR2) (Table 8) is crucial for chloroplast biogenesis and repair of photosystem II (PSII). Variegation is an obvious phenotype because parts of the green tissues appear white (Figure 9c). Instead of chloroplasts, white tissues of var2 mutants contain undifferentiated plastids that lack the typical thylakoids $(19,87)$. Plastids in dark-grown var 2 seedlings (etioplasts) resemble those in wild-type, but fail to differentiate in the light (18). The white sectors are initially yellow and are found in all green organs of the plant (leaves, stems, and siliques), except the cotyledons $(19,60)$. Eight var2 alleles have been described, each displays different degrees of variegation $(18,19,77,87)$. VAR2 is a nuclear gene that encodes an ATP-dependent FtsH metalloprotease $(18,87)$ (Figure 9a).
Variegation: patchiness of pigmentation of leaves and other organs 
Thylakoids:

disc-shaped chloroplast stroma that carry the photosynthetic apparatus membrane vesicles in

VAR2 proteins accumulate in the thylakoid membrane with the domains for ATP binding and proteolysis facing the stroma (18).

Variegation in var2 mutants also depends on VAR2 homologs. VAR2 (FtsH2) is one of $12 \mathrm{FtsH}$ proteases encoded by the Arabidopsis genome $(77,102)$. The closest homolog of VAR2 is FtsH8. Although ftsh 8 mutants do not have a phenotype (77), FtsH8 overexpression can suppress the var 2 phenotype (102) and the var2/ftsh 8 double mu-
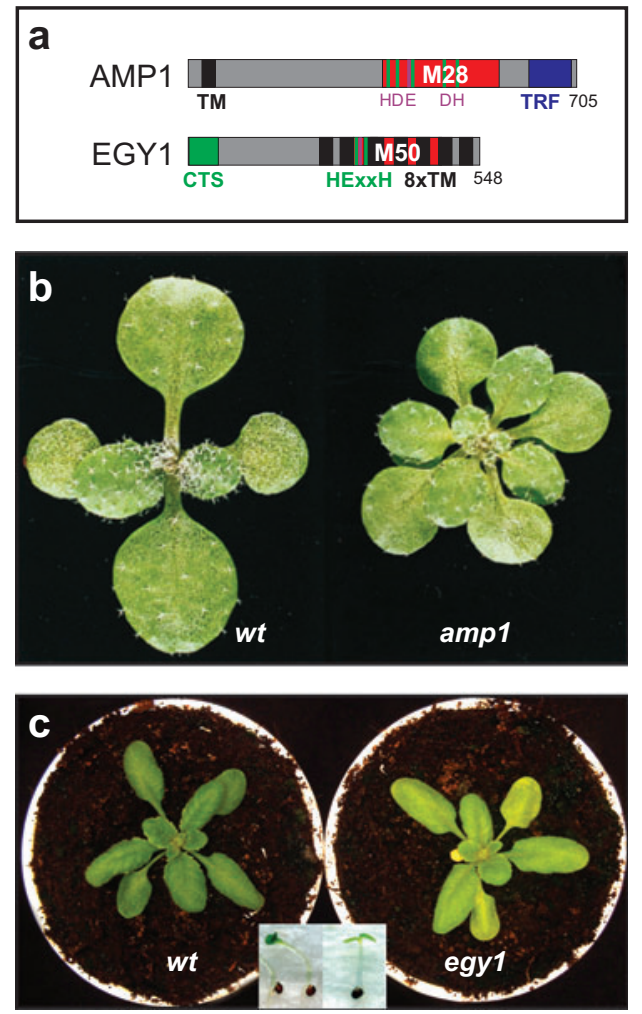

Figure 10

AMP1 and EGY1 (a) Domains of altered meristem program 1 (AMP1) and ethylene-dependent gravitropism-deficient yellow-green 1 (EGY1) proteins. CTS, chloroplast targeting sequence (green); TM, transmembrane domain (black); TRF, TATA binding protein-related factors (TRF) dimer motif (dark blue); M28/M50, protease domain (red); E, catalytic residue Glu (purple); HExxH, H, D, zinc-ion binding residues (green). (b) amp1 mutants display an enlarged shoot apical meristem that generates more organs. Reprinted with permission from Reference 22, Copyright 1997, National Academy of Sciences, U. S. A. (c) egy1 mutants display yellowish leaves with underdeveloped plastids and a hampered shoot gravitropism (inset). Pictures kindly provided by Dr. N. Li (Hong Kong University of Science and Technology, Hong Kong, China). tant is completely white and can only survive on sugar-containing medium (104). These results suggest that VAR2 and $\mathrm{FtsH} 8$ act redundantly and support the hypothesis that FtsH8 compensates for the lack of VAR2 in the green sectors of var 2 mutant plants (102). Sector formation could arise from clonal propagation of cells that contain malfunctioning proplastids early during leaf development (102). VAR1 (FtsH5) is one of the other chloroplastic FtsH proteases, and var1 mutant plants display a less severe variegation compared with var2 (60). Similar to var2, the var1 phenotype can be suppressed by overexpression of its closest homolog, FtsH1 (103), and var1/ftsh1 double mutants are completely white (104). VAR1 and VAR2 proteins form heterocomplexes that become unstable if one of the complex partners is missing $(77,102)$.

Apart from its role in chloroplast biogenesis, VAR2 is also essential for the repair of photosystem II by removal of the photodamaged D1 protein (3). However, hampered repair of photosystem II is probably not the cause of nonfunctional plastids in white sectors because these plastids are underdeveloped and not a result of photobleaching (47). This result suggests that VAR2 plays a role in chloroplast biogenesis, perhaps in the regulation of the formation of thylakoids by the accumulation of VAR2-containing complexes during chloroplast development.

\section{Metalloproteases AMP1 and EGY1}

Two more metalloproteases are discussed here: AMP1 (family M28, clan MH) and EGY1 (family M50, clan MM). These clans are not related to each other evolutionarily or structurally. Family M28 of clan MH contains proteases that are folded as a sixstranded $\beta$-sheet surrounded by helices; the active site contains two cocatalytic zinc ions (Figure 10a). Family M50 of clan MM contains proteases that are membrane-bound and contain a HExxH motif that probably binds a single zinc ion (Figure 10a). The catalytic site may be in the membrane because it is part 
Table 9 Metalloproteases AMP1 (altered meristem program 1) and EGY1 (ethylene-dependent gravitropism-deficient yellow-green 1)

\begin{tabular}{|c|c|c|}
\hline Gene name & $A M P 1$ & $E G Y 1$ \\
\hline Described alleles & 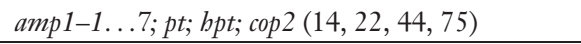 & egy $1-1 . .3(15)$ \\
\hline Knockout phenotype & $\begin{array}{l}\text { Polycotyly, more leaves, larger shoot apical } \\
\text { meristem }(14,22,44,62)\end{array}$ & $\begin{array}{l}\text { Less chlorophyl, no gravitropism, fewer seeds } \\
\text { (15) }\end{array}$ \\
\hline Knockdown phenotype & Not reported & Not reported \\
\hline $\begin{array}{l}\text { Overexpression } \\
\text { phenotype }\end{array}$ & Not reported & Not reported \\
\hline Endogenous expression & Throughout the plant (39) & Throughout the plant, lower in roots (15) \\
\hline Subcellular localization & Unknown & Chloroplast membrane (EGY1-GFP) (15) \\
\hline Genetic interactors & $\begin{array}{l}\text { Independent from } c l v 1 \text { and } c l v 3 \text { (clavata } 1 \text { and } 3) \\
\text { (62); suppressor of monopterous }(m p) \text { (94) }\end{array}$ & Not reported \\
\hline Proteolytic activity & Not reported & Degrades $\beta$-casein in vitro (15) \\
\hline Putative mechanism & $\begin{array}{l}\text { May release peptides that promote } \\
\text { differentiation or inactivate peptides that } \\
\text { suppress differentiation (39) }\end{array}$ & $\begin{array}{l}\text { May regulate the assembly and maintenance of } \\
\text { photosystem II complexes (15) }\end{array}$ \\
\hline
\end{tabular}

of a predicted transmembrane domain, but so far no tertiary structure is available to confirm this topology.

AMP1. Altered meristem program 1 (AMP1) (Table 9) restricts the size of the shoot apical meristem by promoting differentiation. $A M P 1$ has many names because it was identified from many forward genetic screens and has a series of obvious phenotypes: amp1 seedlings grow in the dark as though they are growing in the light [hence cop2, constitutive photomorphogenesis $(14,41)]$, frequently have more than two cotyledons [hence $h p t$, bauptling (44)], and generate leaves in whorls of three instead of one by one [hence $p t$, primordia timing (22)] (Figure 10b). A reduced apical dominance also makes amp1 mutant plants bushier, the rate of leaf formation is doubled, and the plants flower earlier (14, $22,62)$. The amp1 mutation causes male and female semisterility, which results in shorter siliques and fewer seeds $(14,62)$. The earliest amp 1 phenotype during embryogenesis appears at the second division of the zygote. The basal cell normally divides transversely to generate the suspensor, but in amp1 mutant embryos the cells in the apical region of the suspensor undergo a series of vertical divisions to generate cells that become incorpo- rated into an oversized shoot apical meristem (SAM) $(22,94)$. The SAM stays large throughout development and causes the initiation of mutiple organs. This phenotype suggests that in wild-type plants AMP1 promotes differentiation, which keeps the SAM small (94). Mutant amp1 plants produce more cytokinin, probably as a result of the increased SAM size $(14,22,39,62)$. A larger SAM also occurs in clavata (clv) mutants. However, amp1/clv1 and amp1/clv3 double mutants show additive effects on SAM size, which indicates that AMP1 acts independently of the CLV1/3 pathway (62). AMP1 interacts genetically with MONOPTEROUS (MP), an auxin-response factor that acts with the Aux/IAA family in transcriptional regulation (94). Phenotypes of $m p$ mutants are the opposite of amp1 mutant phenotypes, and are suppressed in amp1/mp double mutants (94). This suggests that in wild-type plants, MP counteracts AMP1 by carving out meristematic niches by locally overcoming the differentiationpromoting activity of AMP1 (94). The data suggest that AMP1 releases signaling peptides that promote differentiation at the SAM border or inactivates signaling proteins that suppress differentiation $(39,94)$. Molecular details of these signaling pathways remain to be investigated.
Shoot apical meristem (SAM): population of dividing cells at the tip of the shoot axis 
Gravitropic

response: growth in relation to gravity

Grana: stack of thylakoids in chloroplasts

Amyloplast: colorless starch-forming plastid
EGY1. Ethylene-dependent gravitropismdeficient yellow-green 1 (EGY1) (Table 9) is a chloroplast intermembrane metalloprotease, essential for plastid development and shoot gravitropism. egy1 mutants were identified from a genetic screen for mutants that were both pigmentation deficient and defective in ethylene-stimulated hypocotyl gravitropic responses (15). Instead of normal chloroplasts, egy 1 mutants contain plastids that have fewer stromal thylakoids, no grana and fewer starch grains. The egy1 mutants also accumulate significantly fewer
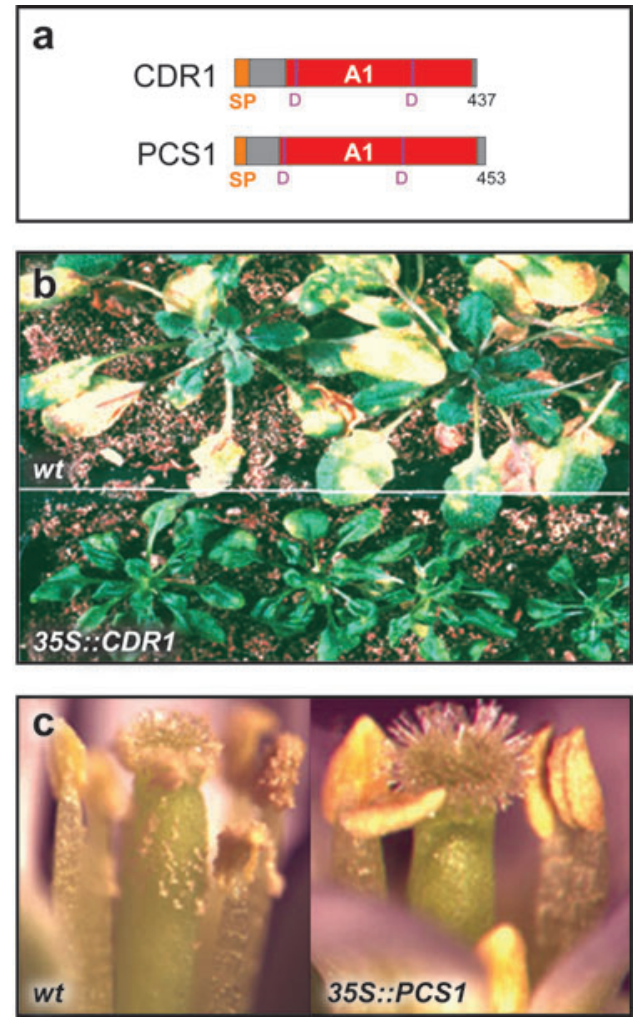

Figure 11

CDR1 and PCS1 (a) Domains of constitutive disease resistance 1 (CDR1) and promotion of cell survival 1 (PCS1) proteins. SP, signal peptide (orange); A1, protease domain (red); D, catalytic residue Asp (purple). (b) CDR1-overexpressing plants are semidwarfed and show enhanced disease resistance to infections with Pseudomonas bacteria. Reprinted from Reference 98 with permission from Macmillan Publishers Ltd. (c) PCS1 overexpression prevents pollen release from anthers because programmed cell death is blocked in specific anther cell types. Reprinted from

Reference 34 with permission from Macmillan Publishers Ltd. chlorophyll $\mathrm{a} / \mathrm{b}$ binding (CAB) proteins, which are part of photosystem II antennae in the thylakoid membrane (15). Hampered photosynthesis explains the reduced growth rate, lower seed number, and the yellowish color (Figure 10c). However, the absence of the shoot gravitropism response in egy1 mutants is unexplained, although chloroplasts in the endodermis of egy $1 \mathrm{mu}-$ tants may not differentiate into amyloplasts, which are the plastids required for the gravitropic response (15). EGY1 contains eight transmembrane helices and resides in the membrane of chloroplasts where it may regulate the maintenance and assembly of PSII complexes by intermembrane proteolysis. This is consistent with the accumulation of the EGY1 protein in chloroplasts in response to light (15). Interestingly, although EGY1 and VAR2 probably both act on the maintenance of photosystem II, their roles are likely different given the differences in phenotypes.

\section{ASPARTIC PROTEASES}

Aspartic proteases contain two aspartic residues, which support a water molecule that acts as the nucleophile during proteolysis. Only three families of aspartic proteases exist in plants, but these families are so large that aspartic proteases make up the second-largest protease class in plants. Biological roles for aspartic proteases are only known for two pepsin-like proteases in family A1 of clan AA.

\section{Pepsin-Like Proteases CDR1 and PCS1}

Pepsin-like proteases (family A1, clan AA) are endopeptidases that are most active at acidic $\mathrm{pH}$. The enzymes are produced as preproproteases and are often secreted from cells as inactive, glycosylated enzymes that activate autocatalytically at acidic $\mathrm{pH}$ (Figure 11a). The three-dimensional structure reveals traces of ancient gene duplication: Pepsin-like proteases comprise 
two highly homologous lobes, each contains a homologous catalytic aspartate residue that forms the active site between the two lobes (69). The Arabidopsis genome encodes approximately 70 pepsin-like proteases, which can be divided into five subfamilies (8). CDR1 and PCS1 are typical pepsin-like proteases, with very different biological roles.

CDR1. Constitutive disease resistance 1 (CDR1) (Table 10) acts in disease resistance signaling. CDR1 was identified by activation tagging (98). CDR1 overexpression suppresses disease caused by virulent strains of the pathogenic bacterium Pseudomonas syringae (Figure 11b). This reduced susceptibility is explained by a constitutive upregulation of defense responses in CDR1-overexpressing plants, including microlesions, high levels of reactive oxygen intermediates (ROIs) and salicylic acid (SA), and constitutive expression of pathogenesis-related (PR) genes $(86,98)$. The constitutive defense response explains why $C D R 1$-overexpressing plants are smaller and their leaves are darker and curled compared with wild-type (Figure $11 \boldsymbol{b}$ ). None of these phenotypes occurs when CDR1 overexpressing plants also express the bacterial NabG gene, which encodes an enzyme that converts SA into cathechol. This result indicates that $\mathrm{SA}$ is required for $C D R 1$-induced responses (98). CDR1-knockout lines are not available, but antisense CDR1 lines are more susceptible to virulent Pseudomonas strains, which indicates that endogenous CDR1 also acts in defense responses (98). Active site mutants of CDR1 could not trigger resistance when overexpressed, which indicates that CDR1 protease activity is required for CDR1 function (98). The CDR1 protein displays proteolytic activity and accumulates in the extracellular space of plants during pathogen attack $(86,98)$. CDR1 activity may release small peptides in the apoplast that can systemically induce $P R$ gene expression (98). Thus, CDR1 activity may lead to the generation of an endogenous extracellular elicitor that could act as a mobile signal for the induction of systemic acquired resistance (SAR).

PCS1. Promotion of cell survival (PCS1) (Table 10) is an endoplasmic reticulum (ER)-resident aspartic protease that prevents
Pathogenesisrelated genes (PR genes): genes that are upregulated during pathogen infection

Systemic acquired resistance (SAR): activation of defense in uninfected parts of a plant

Table 10 Pepsin-like proteases CDR1 (constitutive disease resistance 1) and PCS1 (promotion of cell survival 1)

\begin{tabular}{|c|c|c|}
\hline Gene name & CDR1 & PCS1 \\
\hline Described alleles & Unknown & pcs1 (34) \\
\hline Knockout phenotype & Not reported & $\begin{array}{l}\text { Degeneration of pollen and abortion of } \\
\text { ovules and embryos (34) }\end{array}$ \\
\hline Knockdown phenotype & $\begin{array}{l}\text { Enhanced susceptibility to infection with } \\
\text { Pseudomonas bacteria (98) }\end{array}$ & Not reported \\
\hline $\begin{array}{l}\text { Overexpression } \\
\text { phenotype }\end{array}$ & $\begin{array}{l}\text { Semidwarfing; constitutive disease resistance } \\
(86,98)\end{array}$ & $\begin{array}{l}\text { Blocks programmed cell death in anther } \\
\text { dehiscence (34) }\end{array}$ \\
\hline Endogenous expression & $\begin{array}{l}\text { Ubiquitous and slightly upregulated during } \\
\text { pathogen infection (98) }\end{array}$ & $\begin{array}{l}\text { Only in gametophytes and developing } \\
\text { seeds (34) }\end{array}$ \\
\hline Subcellular localization & $\begin{array}{l}\text { Secreted (predicted) CDR1-GFP is in the cell wall } \\
\text { and endoplasmic reticulum, and CDR1 is in the } \\
\text { apoplast }(86,98)\end{array}$ & $\begin{array}{l}\text { Endoplasmatic reticulum (EndoH } \\
\text { sensitive; PCS1-GFP) (34) }\end{array}$ \\
\hline Genetic interactors & $\begin{array}{l}\text { CDR1 overexpression phenotypes are absent in } \\
\text { salicylic acid (SA)-deficient } N a b G \text { lines (98) }\end{array}$ & Not reported \\
\hline Proteolytic activity & Cleaves bovine serum albumin in vitro $(86,98)$ & Cleaves casein in vitro (34) \\
\hline Putative mechanism & $\begin{array}{l}\text { Could generate endogenous extracellular peptides } \\
\text { that act as mobile signals for systemic acquired } \\
\text { resistance }(86,98)\end{array}$ & $\begin{array}{l}\text { May release survival factors or inactivate } \\
\text { death signals (34) }\end{array}$ \\
\hline
\end{tabular}


cell death during gametogenesis and embryogenesis. When knockout lines for aspartic proteases were investigated, homozygous pcs 1 plants could not be obtained (34). Further investigation revealed that a third of the pollen and ovules from heterozygous pcs $1 /+$ plants are degenerated, and the embryos die before the torpedo stage (34). Consistent with the observed phenotypes, PCS1 gene expression is specific to developing gametophytes and developing seeds (34). However, when ectopically overexpressed, PCS1 blocks PCD in the anther, which prevents the release of pollen because stobium and septum cells in the anther cell wall do not undergo PCD (34) (Figure 11c). Biochemical studies show that PCS1 has proteolytic activity, but how this activity contributes to its function remains to be demonstrated. Intriguingly, deglycosylation experiments and experiments with GFP-fusion proteins demonstrated that PCS1 is localized to the ER (34). The phenotypes can be explained by a role for PCS1 in the prevention of cell death in certain cell types. PCS1 is likely involved in the proteolytic release of survival factors or the inactivation of death signals.

\section{CONCLUSIONS}

The biological roles of plant proteases are strikingly diverse (Figure 12). Protease functions have been identified for different stages in the life of a plant: meiosis (MPA1); gametophyte survival (PCS1); suspensor formation (mcII-Pa); embryo cuticle deposition (ALE1); seed coat formation ( $\delta \mathrm{VPE}$ ); meristem size (AMP1); epidermal cell fate (DEK1); stomata development (SDD1); chloroplast development (VAR2); plastid development (EGY1); growth (BRS1); UV

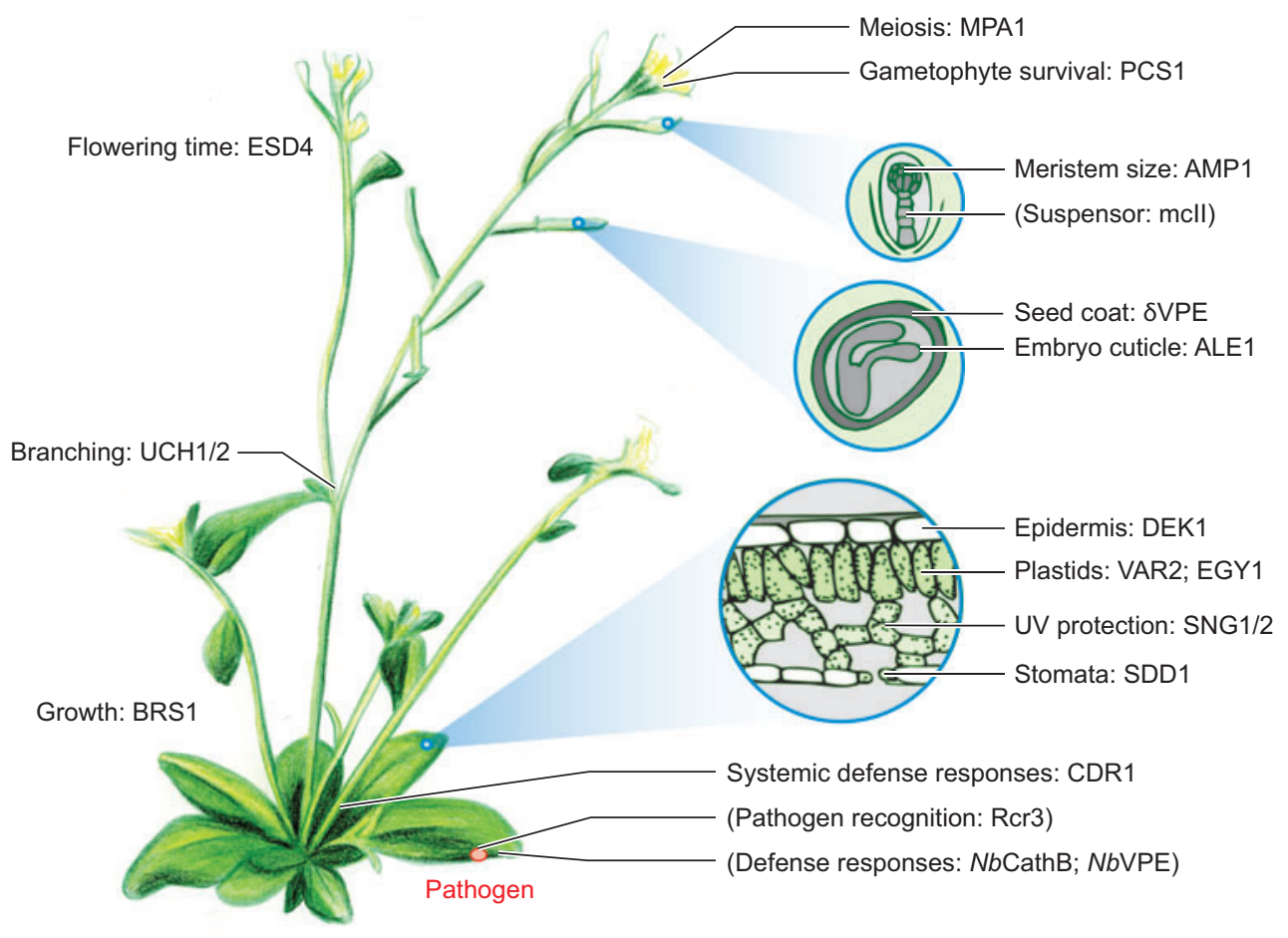

Figure 12

Summary of the biological roles of the discussed proteases. Proteases that were not studied in Arabidopsis are shown in parentheses. 
protection (SNG1); pathogen recognition

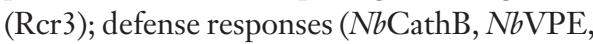
$\gamma \mathrm{VPE})$; systemic defense responses (CDR1); flowering time (ESD4); and branching (UCH1/2).

Proteases are crucial for plants. Protease mutations are frequently lethal (e.g., dek1, ale1, and $p c s 1$ ), and many result in severe fitness-reducing phenotypes (e.g., esd4, var2, egy1, and mpa1), whereas some proteases act redundantly (e.g., VAR2, VPEs, $B R S 1$, and $U C H 1 / 2)$, and are lethal when both genes are mutated (e.g., VAR2/FtsH8). The redundancy and lethality associated with protease mutants limit the opportunities offered by forward and reverse genetics.

The biochemical roles and subcellular locations of proteases are often conserved within the clans. Clan $\mathrm{CA} / \mathrm{CE}$, for example, contains conjugating enzymes, and clans $\mathrm{SB}$ and AA contain secreted proteases. However, there are only weak correlations between biological function and evolutionary relatedness within protease clans. Clan $\mathrm{CD}$, for example, contains proteases that regulate $\mathrm{PCD}$, and $\mathrm{CA}$ clan proteases are often involved in pathogeninduced hypersensitive cell death. For most clans, however, biological functions are very different, e.g., BRS1 and SNG1/2 (clan SB), MPA1 and VAR2 (clan MA), and CDR1 and PCS1 (clan AA). These differences indicate that these protease families did not arise from the evolution of new biological processes, but were recruited from existing protease families during evolution.

Proteases are found at different subcellular locations (Figure 13). Of the 17 discussed proteases, six are secreted into the apoplast (Rcr3，NbCathB， ALE1，SDD1， BRS1, CDR1), two are in the vacuole (VPEs, SNG1/ 2), two are in the chloroplast (VAR2, EGY1), one resides in the ER (PCS1), four are cytoplasmic/nuclear in localization (UCH1/2, ESD4, MPA1, mcII-Pa), and two have unknown subcellular localizations (AMP1, DEK1). Transmembrane domains are found in three of the proteases (DEK1,

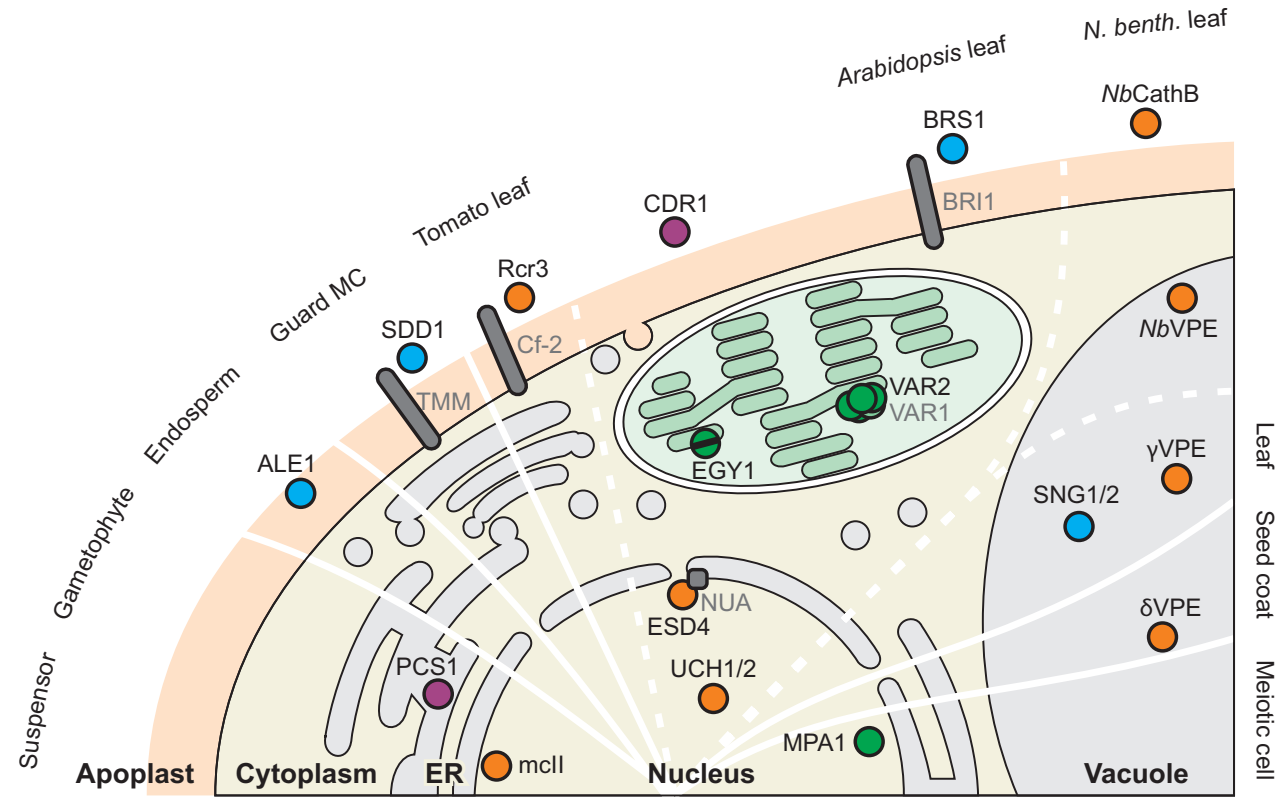

Figure 13

Summary of the subcellular locations of proteases and their interactors, as summarized in this review. 
VAR2, and EGYI), and the others are soluble or associated with membranes.

No biologically relevant substrate has been identified for any of the proteases described so far. However, some proteases do not act through their substrates (e.g., Rcr3), or act by catalyzing nonproteolytic reactions (e.g., SNG1/2). The absence of identified substrates for the other proteases is the major bottleneck for research because it hampers further progress in understanding the molecular basis of how these proteases function.
We know about other proteins that are required for the function of only a few proteases, although the molecular details of these interactions are not yet known. Functions of secreted proteases frequently depend on receptor-like proteins: BRS1 enhances signaling through BRI1, SDD1 signals through TMM, and Rcr3 inactivation by Avr2 is monitored by Cf- 2 . In contrast, VAR2 and ESD 4 physically interact with VAR1 and NUA, respectively; these interactions are essential for their function.

\section{FUTURE ISSUES}

Proteases are crucial in plants, but this field has only just started to unfold. There are phenotypic data for many proteases, but there is still little understanding of their molecular mechanisms. More than 500 proteases remain to be functionally characterized. A daunting task lies ahead to understand the molecular mechanisms of these proteases. The challenge is summarized in the following issues:

1. Where are the proteases localized? This question has already been answered for most proteases, most often via the use of GFP fusion proteins, but for some proteases, like DEK1 and AMP1, this issue remains to be addressed. This task can be challenging because many proteases are processed, which makes it difficult to generate stable GFP-fusion proteins, as described for SDD1.

2. What are the substrates? This question is the hardest to resolve but also the most important. Proteases can cleave many proteins in vitro, but the biologically relevant target substrate is determined not only by substrate specificity, but also by its colocalization with the protease, in both time and space. If there is one major biologically relevant substrate to be cleaved, then this substrate might be identified through forward genetic approaches for suppressors of protease mutant phenotypes. Alternatively, characterization of the protease cleavage specificity and the subcellular location might be used to select and test candidate proteins on the basis of their predicted colocalization, expression, and putative cleavage sites. Other approaches for substrate identification are yeast two-hybrid screening, immobilized protein arrays, and differential proteomics (79), but each of these approaches has its limitations.

3. How are protease activities regulated? This is an intriguing question, but hardly resolved. Many proteases have autoinhibitory domains that are proteolytically removed during activation, but the molecular mechanism of this activation is often unclear. The activity of many proteases is probably also controlled by endogenous inhibitors, but their identity is also unknown. Another layer of regulation comes from environmental conditions such as $\mathrm{pH}$, calcium ions, ATP, and redox status. These issues are poorly described, but are fundamental to understand when and where the protease is active. Fluorescent activity-based probes and substrates are useful tools to image the space and time of protease activities (5), but their potential remains to be exploited. 
4. How do proteases contribute to the phenotype? This bigger picture requires knowledge of not only the identity of the substrate, but also of other components that are part of the network in which the protease functions, such as receptors and transcription factors. Putting all this knowledge together should provide a systems biology model that explains how the protease is incorporated into the network that leads to the phenotype.

5. What is the biological function of the remaining $>500$ proteases? As described above, protease functions differ tremendously, even within families of related proteases. This makes it difficult to predict the biological function of a protease. Reverse genetics, via the use of RNAi approaches, T-DNA lines, or overexpression, may reveal phenotypes. This approach, however, may not be successful if the protease acts redundantly with family members. Pharmacological approaches can offer another approach to annotate functions to proteases. This approach also allows a choice of time point, dosage, and specificity of chemical interference.

\section{DISCLOSURE STATEMENT}

The author is not aware of any biases that might be perceived as affecting the objectivity of this review.

\section{ACKNOWLEDGMENTS}

I am extremely grateful to Dr. Réka Tóth, Dr. Monika Kalde, Dr. Nabil Elrouby, Dr. Farnusch Kaschani, and the members of the Plant Chemetics lab for critically reading the manuscript and providing helpful suggestions. I would like to thank Dr. Vierstra, Dr. Li, Dr. Elrouby, Dr. Ingham, Dr. Gilroy, and Dr. Bozhkov for kindly providing pictures and suggestions.

\section{LITERATURE CITED}

1. Ahn JW, Kim M, Lim JH, Kim GT, Pai HS. 2004. Phytocalpain controls the proliferation and differentiation fates of cells in plant organ development. Plant 7. 38:969-81

2. Avrova AO, Taleb N, Rokka VM, Heilbronn J, Hein I, et al. 2004. Potato oxysterol binding protein and cathepsin B are rapidly up-regulated in independent defence pathways that distinguish $R$ gene-mediated and field resistances to Phytophthora infestans. Mol. Plant Pathol. 5:45-56

3. Bailey S, Thompson E, Nixon PJ, Horton P, Mullineaux CW, et al. 2002. A critical role for the VAR2 FtsH homologue or Arabidopsis thaliana in the photosystem II repair cycle in vivo. F. Biol. Chem. 277:2006-11

4. Bartel B, Fink GR. 1995. ILR1, an aminohydrolase that releases active indole-3-acetic acid from conjugates. Science 268:1745-48

5. Baruch A, Jeffery DA, Bogyo M. 2004. Enzyme activity-it's all about image. Trends Cell Biol. 14:29-35

6. Becraft PW, Asuncion-Crabb Y. 2000. Positional cues specify and maintain aleurone cell fate in maize endosperm. Development 127:4039-48

7. Becraft PW, Li K, Dey N, Asuncion-Crabb Y. 2002. The maize dek1 gene functions in embryonic pattern formation and cell fate specification. Development 129:5217-25 
8. Beers EP, Jones AM, Dickerman AW. 2004. The S8 serine, C1A cysteine and A1 aspartic protease families in Arabidopsis. Phytochemistry 65:43-58

9. Berger D, Altmann T. 2000. A subtilisin-like serine protease involved in the regulation of stomatal density and distribution in Arabidopsis thaliana. Genes Dev. 14:1119-31

10. Bölter B, Nada A, Fulgosi H, Soll J. 2006. A chloroplastic inner envelope membrane protease is essential for plant development. FEBS Lett. 580:789-94

11. Bozhkov PV, Filonova LH, Suarez MF, Helmersson A, Smertenko AP, et al. 2004. VEIDase is a principal caspase-like activity involved in plant programmed cell death and essential for embryonic pattern formation. Cell Death Differ. 11:175-83

12. Bozhkov PV, Suarez MF, Filonova LH, Daniel G, Zamyatnin AA Jr, et al. 2005. Cysteine protease mcII-Pa executes programmed cell death during plant embryogenesis. Proc. Natl. Acad. Sci. USA 102:14463-68

13. Casamitjana-Martínez E, Hofhuis HF, Xu J, Liu CM, Heidstra R, Scheres B. 2003. Rootspecific CLE19 overexpression and the sol1/2 suppressors implicate a CLV-like pathway in the control of Arabidopsis root meristem maintenance. Curr. Biol. 13:1435-41

14. Chaudhurry AM, Letham S, Craig S, Dennis ES. 1993. amp1-a mutant with high cytokinin levels and altered embryonic pattern, faster vegetative growth, constitutive photomorphogenesis and precocious flowering. Plant 7. 4:907-16

15. Chen G, Bi YR, Li N. 2005. EGY1 encodes a membrane-associated and ATP-independent metalloprotease that is required for chloroplast development. Plant 7. 41:364-75

16. Chen J, Burke JJ, Velten J, Xin Z. 2006. FtsH11 protease plays a critical role in Arabidopsis thermotolerance. Plant 7. 48:73-84

17. Chen JM, Rawlings ND, Stevens RAE, Barrett AJ. 1998. Identification of the active site of legumain links it to caspases, clostripain and gingipains in a new clan of cysteine endopeptidases. FEBS Lett. 441:361-65

18. Chen M, Choi YD, Voytas DF, Rodermel S. 2000. Mutations in the Arabidopsis VAR2 locus cause leaf variegation due to the loss of a chloroplast FtsH protease. Plant 7. 22:303-13

19. Chen M, Jensen M, Rodermel S. 1999. The yellow variegated mutant of Arabidopsis is plastid autonomous and delayed in chloroplast biogenesis. F. Heredity 90:207-14

20. Colby T, Matthäi A, Boeckelmann A, Stuible HP. 2006. SUMO-conjugating and SUMOdeconjugating enzymes from Arabidopsis. Plant Physiol. 142:318-32

21. Combier JP, Vernié T, de Billy F, El Yahyaoui F, Mathis R, Gamas P. 2007. The $M t$ MMPL1 early nodulin is a novel member of the matrix metalloendoproteinase family with a role in Medicago truncatula infection by Sinorbizobium meliloti. Plant Physiol. 144:703-16

22. Conway LJ, Poethig RS. 1997. Mutations of Arabidopsis thaliana that transform leaves into cotyledons. Proc. Natl. Acad. Sci. USA 94:10209-14

23. Davies RT, Goetz DH, Lasswell J, Anderson MN, Bartel B. 1999. IAR3 encodes an auxin conjugate hydrolase from Arabidopsis. Plant Cell 11:365-76

24. Dixon MS, Golstein C, Thomas CM, van Der Biezen EA, Jones JDG. 2000. Genetic complexity of pathogen perception by plants: the example of $\operatorname{Rcr} 3$, a tomato gene required specifically by Cf-2. Proc. Natl. Acad. Sci. USA 97:8807-14

25. Dixon MS, Jones DA, Keddie JS, Thomas CM, Harrison K, Jones JD. 1996. The tomato Cf-2 disease resistance locus comprises two functional genes encoding leucine-rich repeat proteins. Cell 84:451-59

26. Doelling JH, Soyler-Orgretim G, Phillips AR, Otegui MS, Chandler JS, et al. 2007. The ubiquitin-specific protease subfamily UBP3 and UBP4 is essential for pollen development in Arabidopsis thaliana. Plant Physiol. In press 
27. Doelling JH, Yan N, Kurepa J, Walker J, Vierstra RD. 2001. The ubiquitin-specific protease UBP14 is essential for early embryo development in Arabidopsis thaliana. Plant 7. 27:393-405

28. Downes B, Vierstra RD. 2005. Post-translational regulation in plants employing a diverse set of polypeptide tags. Biochem. Soc. Trans. 33:393-99

29. Drenth J, Jansoniu J, Koekoek R, Swen HM, Wolters BG. 1968. Structure of papain. Nature 218:929-32

30. Dunn BM. 2001. Determination of protease mechanism. In Proteolytic Enzymes: A Practical Approach, ed. R Beynon, JS Bond, pp. 77-104. Oxford: Univ. Press. 2nd ed.

31. Eason JR, Ryan DJ, Watson LM, Hedderley D, Christey MC, et al. 2005. Suppression of the cysteine protease, aleurain, delays floret senescence in Brassica oleracea. Plant Mol. Biol. 57:645-57

32. Fraser CM, Rider LW, Chapple C. 2005. An expression and bioinformatics analysis of the Arabidopsis serine carboxypeptidase-like gene family. Plant Physiol. 138:1136-48

33. García-Lorenzo M, Sjödin A, Jansson S, Funk C. 2006. Protease gene families in Populus and Arabidopsis. BMC Plant Biol. 6:30

34. Ge X, Dietriech C, Matsuno M, Li G, Berg G, et al. 2005. An Arabidopsis aspartic protease functions as an anti-cell-death component in reproduction and embryogenesis. EMBO Rep. 6:282-88

35. Gilroy E, Hein I, van der Hoorn RAL, Boevink P, Venter E, et al. 2007. Involvement of cathepsin $\mathrm{B}$ in the plant disease resistance hypersensitive response. Plant 7. 53:1-13

36. Golldack D, Popova OV, Dietz KJ. 2002. Mutation of the matrix metalloproteinase At2MMP inhibits growth and causes late flowering and early senescence in Arabidopsis. $\mathcal{F}$. Biol. Chem. 277:5541-47

37. Hara-Nishimura I, Hatsugai N, Nakaune S, Kuroyanagi M, Nishimura M. 2005. Vacuolar processing enzyme: an executor of plant cell death. Curr. Opin. Plant Biol. 8:404-8

38. Hatsugai N, Kuroyanagi M, Nishimura M, Hara-Nishimura I. 2006. A cellular suicide strategy of plants: vacuole-mediated cell death. Apoptosis 11:905-11

39. Helliwell CA, Chin-Atkins AN, Wilson IW, Chapple R, Dennis ES, Chaudhury A. 2001. The Arabidopsis AMP1 gene encodes a putative glutamate carboxypeptidase. Plant Cell 13:2115-25

40. Hosfield CM, Elce JS, Davies PL, Jia Z. 1999. Crystal structure of calpain reveals the structural basis of $\mathrm{Ca}^{2+}$-dependent protease activity and a novel mode of enzyme activation. EMBO F. 18:6880-89

41. Hou Y, Von Arnim AG, Deng XW. 1993. A new class of Arabidopsis constitutive photomorphogenic genes involved in regulating cotyledon development. Plant Cell 5:329-39

42. Inoue K, Baldwin AJ, Shipman RL, Matsui K, Theg SM, Ohme-Takagi M. 2005. Complete maturation of the plasmid protein translocation channel requires a type I signal peptidase. 7. Cell Biol. 171:425-30

43. Johnson KL, Degnan KA, Walker JR, Ingram GC. 2005. AtDEK1 is essential for specification of embryonic epidermal cell fate. Plant 7. 44:114-27

44. Jürgens G, Mayer U, Torres Ruiz R, Berleth T, Misera S. 1991. Genetic analysis of pattern formation in the Arabidopsis embryo. Development 1(Suppl.):27-38

45. Hatsugai N, Kuroyanagi M, Yamada K, Meshi T, Tsuda S, et al. 2004. A plant vacuolar protease, VPE, mediates virus-induced hypersensitive cell death. Science 305:855-58

46. Kapri-Pardes E, Naveh L, Adam Z. 2007. The thylakoid lumen protease Deg1 is involved in the repair of photosystem II from photoinhibition in Arabidopsis. Plant Cell 19:1039-47

47. Kato Y, Miura E, Matsushima R, Sakamoto W. 2007. White leaf sectors in yellow variegated 2 are formed by viable cells with undifferentiated plastids. Plant Physiol. 144:952-60 
48. Kinoshita T, Yamada K, Hiraiwa N, Kondo M, Nishimura M, Hara-Nishimura I. 1999. Vacuolar processing enzyme is up-regulated in the lytic vacuoles of vegetative tissues during senescence and under various stressed conditions. Plant 7. 19:43-53

49. Krüger J, Thomas CM, Golstein C, Dixon MS, Smoker M, et al. 2002. A tomato cysteine protease required for $\mathrm{Cf}$-2-dependent disease resistance and suppression of autonecrosis. Science 296:744-47

50. Kuroda H, Maliga P. 2003. The plastid $c l p P 1$ protease gene is essential for plant development. Nature 425:86-89

51. Kuroyanagi M, Yamada K, Hatsugai N, Kondo M, Nishimura M, Hara-Nishimura I. 2005. Vacuolar processing enzyme is essential for mycotoxin-induced cell death in Arabidopsis thaliana. F. Biol. Chem. 280:32914-20

52. Lehfeldt C, Shirley AM, Meyer K, Ruegger MO, Cusumano JC, et al. 2000. Cloning of the SNG1 gene of Arabidopsis reveals a role for a serine carboxypeptidase-like protein as an acyltransferase in secondary metabolism. Plant Cell 12:1295-306

53. Li AX, Steffens JC. 2000. An acyltransferase catalysing the formation of diacylglucose is a serine carboxypeptidase-like protein. Proc. Natl. Acad. Sci. USA 97:6902-7

54. Li J, Lease KA, Tax FE, Walker JC. 2001. BRS1, a serine carboxypeptidase, regulates BRI1 signaling in Arabidopsis thaliana. Proc. Natl. Acad. Sci. USA 98:5916-21

55. Lid SE, Gruis D, Jung R, Lorentzen JA, Ananiev E, et al. 2002. The defective kernel 1 (dek1) gene required for aleurone cell development in the endosperm of maize grains encodes a membrane protein of the calpain gene superfamily. Proc. Natl. Acad. Sci. USA 99:5460-65

56. Lid SE, Olsen L, Nestestog R, Aukerman M, Brown RC, et al. 2005. Mutation in the Arabidopsis thaliana DEK1 calpain gene perturbs endosperm and embryo development while overexpression affects organ development globally. Planta 221:339-51

57. Lorenzen M, Racicot V, Strack D, Chapple C. 1996. Sinapic acid ester metabolism in wild type and a sinapoylglucose-accumulating mutant of Arabidopsis. Plant Physiol. 112:1625-30

58. Luderer R, Takken FLW, de Wit PJGM, Joosten MHAJ. 2002. Cladosporium fulvum overcomes $C f$-2-mediated resistance by producing truncated AVR2 elicitor proteins. Mol. Microbiol. 45:875-84

59. Martin MN, Saladores PH, Lambert E, Hudson AO, Leustek T. 2007. Localisation of members of the $\gamma$-glutamyl transpeptidase family identifies sites of glutathione and glutathione S-conjugate hydrolysis. Plant Physiol. 144:1715-32

60. Martinez-Zapater JM. 1993. Genetic analysis of variegated mutants in Arabidopsis. 7. Hered. $84: 138-40$

61. Miura E, Kato Y, Matsushima R, Albrecht V, Laalami S, Sakamoto W. 2007. The balance between protein synthesis and degradation in chloroplasts determines leaf variegation in Arabidopsis yellow variegated mutants. Plant Cell 19:1313-28

62. Mordhorst AP, Voerman KJ, Hartog MV, Meijer EA, van Went J, et al. 1998. Somatic embryogenesis in Arabidopsis thaliana is facilitated by mutations in genes repressing meristematic cell divisions. Genetics 149:549-63

63. Mossessova E, Lima CD. 2000. Ulp1-SUMO crystal structure and genetic analysis reveal conserved interactions and a regulatory element essential for cell growth in yeast. Mol. Cell 5:865-76

64. Murtas G, Reeves PH, Fu YF, Bancroft I, Dean C, Coupland G. 2003. A nuclear protease required for flowering-time regulation in Arabidopsis reduces the abundance of SMALL UBIQUITIN-RELATED MODIFIER conjugates. Plant Cell 15:2308-19 
65. Nakaune S, Yamada K, Kondo M, Kato T, Tabata S, et al. 2005. A vacuolar processing enzyme, $\delta \mathrm{VPE}$, is involved in seed coat formation at the early stage of seed development. Plant Cell 17:876-87

66. Park S, Rodermel SR. 2004. Mutations in ClpC2/Hsp100 suppress the requirement for FtsH in thylakoid membrane biogenesis. Proc. Natl. Acad. Sci. USA 101:12765-70

67. Pechan T, Ye L, Chang Y, Mitra A, Lin L, et al. 2000. A unique 33-kD cysteine proteinase accumulates in response to larval feeding in maize genotypes resistant to fall armyworm and other Lepidoptera. Plant Cell 12:1031-40

68. Rautergarten C, Steinhauser D, Büssis D, Stintzi A, Schaller A, et al. 2005. Inferring hypothesis on functional relationships of genes: analysis of the Arabidopsis thaliana subtilase gene family. PLoS Comput. Biol. 1:297-312

69. Rawlings ND, Morton FR, Barrett AJ. 2006. MEROPS: the peptidase database. Nucleic Acids Res. 34:D270-72

70. Reeves PH, Murtas G, Dash S, Coupland G. 2002. Early in short days 4, a mutation in Arabidopsis that causes early flowering and reduces the mRNA abundance of the floral repressor FLC. Development 129:5349-61

71. Rojo E, Martin R, Carter C, Zouhar J, Pan S, et al. 2004. VPE $\gamma$ exhibits a caspase-like activity that contributes to defense against pathogens. Curr. Biol. 14:1897-906

72. Rooney HCE, van't Klooster JW, van der Hoorn RAL, Joosten MHAJ, Jones JDG, de Wit PJGM. 2005. Cladosporium Avr2 inhibits tomato Rcr3 protease required for Cf-2-dependent disease resistance. Science 308:1783-86

73. Rupinder SK, Gurpreet AK, Manjeet S. 2007. Cell suicide and caspases. Vascular Pharmacol. 46:383-93

74. Saez ME, Ramirez-Lorca R, Moron FJ, Ruiz A. 2006. The therapeutic potential of the calpain family: new aspects. Drug Discov. Today 11:917-23

75. Saibo NJM, Vriezen WH, De Grauwe L, Azmi A, Prinsen E, Van der Straeten D. 2007. A comparative analysis of the Arabidopsis ampi1-1 and a novel weak amp1 allele reveals new functions of the AMP1 protein. Planta 225:831-42

76. Sakamoto W, Tamura T, Hanba-Tomita Y, Sodmergen, Murata M. 2002. The VAR1 locus of Arabidopsis encodes a chloroplastic FtsH and is responsible for leaf variegation in the mutant alleles. Genes Cells 7:769-80

77. Sakamoto W, Yaltsman A, Adam Z, Takahashi Y. 2003. Coordinated regulation and complex formation of YELLOW VARIEGATED1 and YELLOW VARIEGATED2, chloroplastic FtsH metalloproteases involved in the repair cycle of photosystem II in Arabidopsis thylakoid membranes. Plant Cell 15:2843-55

78. Sanchez-Moran E, Jones GH, Franklin CH, Santos JL. 2004. A puromycin-sensitive aminopeptidase is essential for meiosis in Arabidopsis thaliana. Plant Cell 16:2895-909

79. Schilling O, Overall CM. 2007. Proteomic discovery of protease substrates. Curr. Opin. Chem. Biol. 11:36-45

80. Shen G, Yan J, Pasapula V, Luo J, He C, et al. 2007. The chloroplast protease subunit $\mathrm{ClpP} 4$ is a substrate of the $\mathrm{E} 3$ ligase AtCHIP and plays an important role in chloroplast function. Plant 7. 49:228-37

81. Shirley AM, Chapple C. 2003. Biochemical characterisation of sinapoylglucose:choline sinapoyltransferase, a serine carboxypeptidase-like protein that functions as an acyltransferase in plant secondary metabolism. F. Biol. Chem. 278:19870-77

82. Shirley AM, McMichael CM, Chapple C. 2001. The sng2 mutant of Arabidopsis is defective in the gene encoding the serine carboxypeptidase-like protein sinapoylglucose:choline sinapoyltransferase. Plant 7. 28:83-94 
83. Sjögren LLE, Stanne TM, Zheng B, Sutinen S, Clarke AK. 2006. Structural and functional insights into the chloroplast ATP-dependent Clp protease in Arabidopsis. Plant Cell $18: 2635-49$

84. Suarez MF, Filonova LH, Smertenko A, Savenkov EI, Clapham DH, et al. 2004. Metacaspase-dependent programmed cell death is essential for plant embryogenesis. Curr. Biol. 14:R338-40

85. Sun X, Peng L, Guo J, Chi W, Ma J, et al. 2007. Formation of Deg5 and Deg8 complexes and their involvement in the degradation of photodamaged photosystem II reaction center D1 protein in Arabidopsis. Plant Cell 19:1347-61

86. Suzuki H, Xia Y, Cameron R, Shadle G, Blount J, et al. 2003. Signals for local and systemic responses of plants to pathogen attack. F. Exp. Bot. 55:169-79

87. Takechi K, Sodmergen, Murata M, Motoyoshi F, Sakamoto W. 2000. The YELLOW VARIEGATED (VAR2) locus encodes a homologue of FtsH, an ATP dependent protease in Arabidopsis. Plant Cell Physiol. 41:1334-46

88. Tanaka H, Onouchi H, Kondo M, Hara-Nishimura I, Nishimura M, et al. 2001. A subtilisin-like serine protease is required for epidermal surface formation in Arabidopsis embryos and juvenile plants. Development 128:4681-89

89. Tanaka H, Watanabe M, Sasabe M, Hiroe T, Tanaka T, et al. 2007. Novel receptorlike kinase ALE2 controls shoot development by specifying epidermis in Arabidopsis. Development 134:1643-52

90. Taylor MAJ, Baker KC, Briggs GS, Connerton IF, Cummings NJ, et al. 1995. Recombinant proregions from papain and papaya proteinase IV are selective high affinity inhibitors of the mature papaya enzymes. Protein Eng. 8:59-62

91. van der Biezen EA, Jones JDG. 1998. Plant disease resistance proteins and the gene-forgene concept. Trends Biochem. Sci. 23:454-56

92. van der Hoorn RAL, de Wit PJGM, Joosten MHAJ. 2002. Balancing selection favors guarding resistance proteins. Trends Plant Sci. 7:67-71

93. van der Hoorn RAL, Jones JDG. 2004. The plant proteolytic machinery and its role in defense. Curr. Opin. Plant Biol. 7:400-7

94. Vidaurre DP, Ploense S, Krogan NT, Berleth T. 2007. AMP1 and MP antagonistically regulate embryo and meristem development in Arabidopsis. Development 134:2561-67

95. Von Groll U, Berger D, Altmann T. 2002. The subtilisin-like serine protease SDD1 mediates cell-to-cell signaling during Arabidopsis stomatal development. Plant Cell 14:1527-39

96. Wang C, Barry JK, Min Z, Tordsen G, Rao AG, Olsen OA. 2003. The calpain domain of the maize DEK1 protein contains the conserved catalytic triad and functions as a cysteine protease. 7. Biol. Chem. 278:34467-74

97. Watanabe M, Tanaka H, Watanabe D, Machida C, Machida Y. 2004. The ACR4 receptorlike kinase is required for surface formation of epidermis-related tissues in Arabidopsis thaliana. Plant 7. 39:298-308

98. Xia Y, Suzuki H, Borevitz J, Blount J, Guo Z, et al. 2004. An extracellular aspartic protease functions in Arabidopsis disease resistance signaling. EMBO 7. 23:980-88

99. Xu XM, Rose A, Muthuswamy S, Heong SY, Venkatakrishnan S, et al. 2007. NUCLEAR PORE ANCHOR, the Arabidopsis homolog of Tpr/Mlp2/Megator, is involved in mRNA export and SUMO homeostasis and affects diverse aspects of plant development. Plant Cell. 19:1537-48

100. Yan N, Doelling JH, Falbel TG, Durski AM, Vierstra RD. 2000. The ubiquitin-specific protease family from Arabidopsis. AtUBP1 and 2 are required for the resistance to the amino acid analog canavanine. Plant Physiol. 124:1828-43 
101. Yang P, Smalle J, Lee S, Yan N, Emborg TJ, Vierstra RD. 2007. Ubiquitin C-terminal hydrolases 1 and 2 affect shoot architecture in Arabidopsis. Plant 7. 51:441-57

102. Yu F, Park S, Rodermel SR. 2004. The Arabidopsis FtsH metalloprotease gene family: interchangeability of subunits in chloroplast oligomeric complexes. Plant 7. 37:864-76

103. Yu F, Park S, Rodermel SR. 2005. Functional redundancy of AtFtsH metalloproteases in thylakoid membrane complexes. Plant Physiol. 138:1957-66

104. Zaltsman A, Oir N, Adam Z. 2005. Two types of FtsH protease subunits are required for chloroplast biogenesis and photosystem II repair in Arabidopsis. Plant Cell 17:2782-90

105. Zheng B, MacDonald TM, Sutinen S, Hurry V, Clarke AK. 2006. A nuclear-encoded ClpP subunit of the chloroplast ATP-dependent Clp protease is essential for early development in Arabidopsis thaliana. Planta 224:1101-15

106. Zhou A, Li J. 2005. Arabidopsis BRS1 is a secreted and active serine carboxypeptidase. 7. Biol. Chem. 280:35554-61 
Annual Review of Plant Biology

Our Work with Cyanogenic Plants

Eric E. Conn ........................................................... 1

New Insights into Nitric Oxide Signaling in Plants

Angélique Besson-Bard, Alain Pugin, and David Wendehenne.

Plant Immunity to Insect Herbivores

Gregg A. Howe and Georg Fander

Patterning and Polarity in Seed Plant Shoots

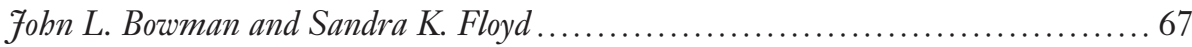

Chlorophyll Fluorescence: A Probe of Photosynthesis In Vivo

Neil R. Baker

Seed Storage Oil Mobilization

Ian A. Graham

The Role of Glutathione in Photosynthetic Organisms:

Emerging Functions for Glutaredoxins and Glutathionylation

Nicolas Roubier, Stéphane D. Lemaire, and Fean-Pierre facquot

Algal Sensory Photoreceptors

Peter Hegemann

Plant Proteases: From Phenotypes to Molecular Mechanisms Renier A.L. van der Hoorn

Gibberellin Metabolism and its Regulation

Shinjiro Yamaguchi

Molecular Basis of Plant Architecture

Yonghong Wang and fiayang $\mathrm{Li}$

Decoding of Light Signals by Plant Phytochromes and Their Interacting Proteins

Gabyong Bae and Giltsu Choi

Flooding Stress: Acclimations and Genetic Diversity

7. Bailey-Serres and L.A.C.7. Voesenek 
Roots, Nitrogen Transformations, and Ecosystem Services

Louise E. Fackson, Martin Burger, and Timothy R. Cavagnaro

A Genetic Regulatory Network in the Development of Trichomes and Root Hairs

Tetsuya Ishida, Tetsuya Kurata, Kiyotaka Okada, and Takuji Wada

Molecular Aspects of Seed Dormancy

Ruth Finkelstein, Wendy Reeves, Tobru Ariizumi, and Camille Steber

Trehalose Metabolism and Signaling

Matthew 7. Paul, Lucia F. Primavesi, Deveraj Fhurreea, and Yuhua Zhang

Auxin: The Looping Star in Plant Development

René Benjamins and Ben Scheres

Regulation of Cullin RING Ligases

Sara K. Hotton and Fudy Callis

Plastid Evolution

Sven B. Gould, Ross F. Waller, and Geoffrey I. McFadden

Coordinating Nodule Morphogenesis with Rhizobial Infection in Legumes

Giles E.D. Oldroyd and 7. Allan Downie

Structural and Signaling Networks for the Polar Cell Growth

Machinery in Pollen Tubes

Alice Y. Cheung and Hen-ming $W u$

Regulation and Identity of Florigen: FLOWERING LOCUS T Moves

Center Stage

Franziska Turck, Fabio Fornara, and George Coupland

Plant Aquaporins: Membrane Channels with Multiple Integrated Functions

Christophe Maurel, Lionel Verdoucq, Doan-Trung Luu, and Véronique Santoni ....595

Metabolic Flux Analysis in Plants: From Intelligent Design

to Rational Engineering

Igor G.L. Libourel and Yair Shachar-Hill

Mechanisms of Salinity Tolerance

Rana Munns and Mark Tester. ...

Sealing Plant Surfaces: Cuticular Wax Formation by Epidermal Cells

Lacey Samuels, Ljerka Kunst, and Reinhard Fetter

Ionomics and the Study of the Plant Ionome

David E. Salt, Ivan Baxter, and Brett Lahner 
Alkaloid Biosynthesis: Metabolism and Trafficking Förg Ziegler and Peter 7. Facchini...

Genetically Engineered Plants and Foods: A Scientist's Analysis of the Issues (Part I)

Peggy G. Lemaux

\section{Indexes}

Cumulative Index of Contributing Authors, Volumes 49-59 813

Cumulative Index of Chapter Titles, Volumes 49-59 818

\section{Errata}

An online log of corrections to Annual Review of Plant Biology articles may be found at http://plant.annualreviews.org/ 